\title{
Review Article \\ Role of Calcium and Mitochondria in MeHg-Mediated Cytotoxicity
}

\author{
Daniel Roos, ${ }^{1}$ Rodrigo Seeger, ${ }^{1}$ Robson Puntel, ${ }^{2}$ and Nilda Vargas Barbosa ${ }^{1}$ \\ ${ }^{1}$ Departamento de Química, CCNE, Programa de Pós-Graduação em Bioquímica Toxicológica, Universidade Federal de Santa Maria, \\ 97105.900 Santa Maria, RS, Brazil \\ ${ }^{2}$ Universidade Federal do Pampa-Campus Uruguaiana, BR-472 Km 7, 97500-970 Uruguaiana, RS, Brazil
}

Correspondence should be addressed to Robson Puntel, robson_puntel@yahoo.com.br and Nilda Vargas Barbosa, nvbarbosa@yahoo.com.br

Received 6 April 2012; Revised 12 June 2012; Accepted 14 June 2012

Academic Editor: Marcelo Farina

Copyright (C) 2012 Daniel Roos et al. This is an open access article distributed under the Creative Commons Attribution License, which permits unrestricted use, distribution, and reproduction in any medium, provided the original work is properly cited.

\begin{abstract}
Methylmercury $(\mathrm{MeHg})$ mediated cytotoxicity is associated with loss of intracellular calcium $\left(\mathrm{Ca}^{2+}\right)$ homeostasis. The imbalance in $\mathrm{Ca}^{2+}$ physiology is believed to be associated with dysregulation of $\mathrm{Ca}^{2+}$ intracellular stores and/or increased permeability of the biomembranes to this ion. In this paper we summarize the contribution of glutamate dyshomeostasis in intracellular $\mathrm{Ca}^{2+} \mathrm{overload}$ and highlight the mitochondrial dysfunctions induced by $\mathrm{MeHg}$ via $\mathrm{Ca}^{2+}$ overload. Mitochondrial disturbances elicited by $\mathrm{Ca}^{2+}$ may involve several molecular events (i.e., alterations in the activity of the mitochondrial electron transport chain complexes, mitochondrial proton gradient dissipation, mitochondrial permeability transition pore (MPTP) opening, thiol depletion, failure of energy metabolism, reactive oxygen species overproduction) that could culminate in cell death. Here we will focus on the role of oxidative stress in these phenomena. Additionally, possible antioxidant therapies that could be effective in the treatment of $\mathrm{MeHg}$ intoxication are briefly discussed.
\end{abstract}

\section{Introduction}

Mercury is one of the most studied heavy metal due to its wide distribution in nature. In the environment, humans and animals can be exposed to different chemical forms of mercury, including elemental mercury vapor $\left(\mathrm{Hg}^{0}\right)$, inorganic mercurous $\left(\mathrm{Hg}^{2++}\right)$, mercuric $\left(\mathrm{Hg}^{++}\right)$, and organic mercuric compounds as ethylmercury, methylmercury, and dimethylmercury $[1,2]$. All forms of mercury can be toxic and the extent of the toxic effects varies depending on the dose, chemical form, and level of exposure. Among the organic forms, methylmercury $(\mathrm{MeHg})$ is the most frequently encountered in the environment. It is formed mainly as the result of methylation of inorganic (mercuric) forms of mercury by microorganisms in aquatic milieu, where it can pass up through the aquatic food chain and bioaccumulates in fish and sea mammals [1] (Figure 1). At present, sea food consumption represents the main human exposure route for $\mathrm{MeHg}$ and the brain is the main target organ for its toxicity. Neurological symptoms induced by $\mathrm{MeHg}$ intoxication can include cerebellar ataxia, paresthesia, dysarthria, mnemic deficits, memory impairment, and sensory disorders $[3,4]$. $\mathrm{MeHg}$ has become a ubiquitous pollutant since outbreak of environmental disasters that occurred in Japan (1950s) and Iraq (1970s) due the consumption of MeHg-contaminated fish and seed grain, respectively [5,6]. Although $\mathrm{MeHg}$ is known to affect adult central nervous system (CNS), these catastrophic episodes revealed the particular sensitivity of immature brain to high concentration of $\mathrm{MeHg}$. Epidemiological evidence also shows that acute or chronic prenatal exposure to low $\mathrm{MeHg}$ levels from maternal consumption of fish can cause neurological deficits in children. Cerebral palsy, mental retardation, deafness, and blindness are some of abnormalities caused by fetal and neonatal $\mathrm{MeHg}$ exposure $[3,4,7,8]$. Despite these observations, there is evidence that the fetal brain is more susceptible than infantile brain to $\mathrm{MeHg}$ toxicity. Differences among gestation stage, exposure duration, and efficacy of antioxidant systems in developing brain might be determinant factors in the age-dependent neuronal vulnerability to $\mathrm{MeHg}[4,8-10]$. 


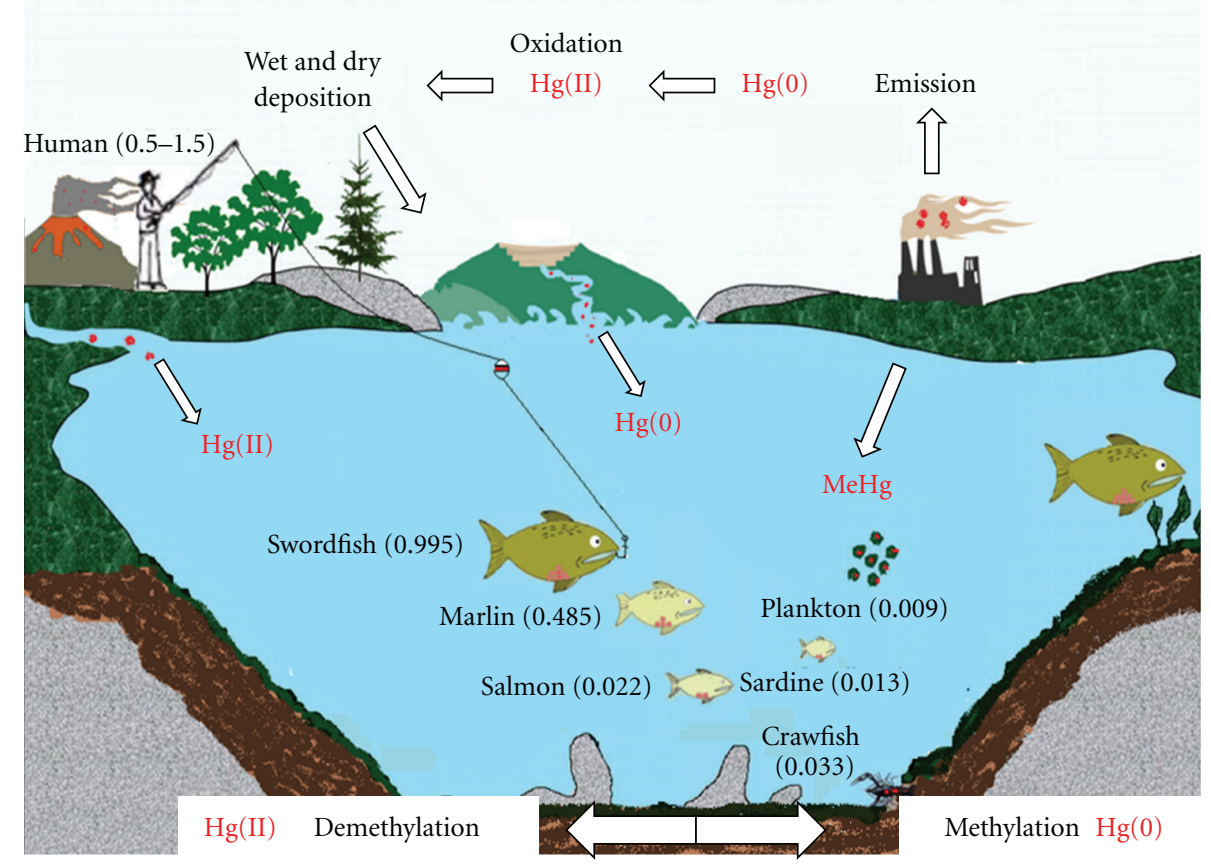

Figure 1: Cycle of mercury and its bioaccumulation in aquatic food chain. The values of mercury levels in the plankton and fish are represented as ppm. All data presented in this figure were obtained from (FDA and EPA).

As a consequence of high affinity of $\mathrm{MeHg}$ for $-\mathrm{SH}$ groups, the molecular interaction between $\mathrm{MeHg}$ and sulfhydryl-containing molecules as L-cysteine, glutathione (GSH), hemoglobin, and albumin has been implicated in the mechanisms involving transport, uptake, and accumulation of $\mathrm{MeHg}$ into living tissues [11]. In this regard, several studies have demonstrated that the cellular uptake of $\mathrm{MeHg}$ is markedly increased when it is present as Cys-MeHg conjugate $[12,13]$ once that this complex by mimicking structurally the amino acid methionine is a substrate for the neutral amino acid carrier L-type [11, 14] (Figure 2).

Different mechanism and molecular targets have been proposed to be involved in $\mathrm{MeHg}$ neurotoxicity. Thiol depletion (especially glutathione), glutamate dyshomeostasis, calcium dysregulation, oxidative stress, cytoskeletal disruption, and mitochondrial dysfunctions are among the detrimental effects known to render neurons vulnerability to $\mathrm{MeHg}$ toxicity $[15,16]$ (Figure 3 ).

One of the most widely documented effects caused by $\mathrm{MeHg}$ on the CNS is associated with glutamate-mediated excitotoxicity, which can be linked to or followed by intracellular $\mathrm{Ca}^{2+}$ overload. In this way, there are a number of experimental findings from in vivo and in vitro studies pointing that the inhibition of glutamate uptake by astrocytes, the increase in spontaneous release of glutamate from presynaptic terminals, and the inhibition of vesicular glutamate uptake are critical phenomena linked to $\mathrm{MeHg}$-mediated excitotoxicity $[15,17,18]$ (Figure 4). In this scenario, the excitatory amino acid receptors (N-methyl D-aspartate (NMDA) and nonNMDA-types) mediated pathways have been indicated as the main routes responsible by $\mathrm{Ca}^{2+}$ entry into cells following
MeHg exposure $[19,20]$. In accordance, a recent study using mouse spinal motor neurons in culture demonstrated that the excitatory amino acid receptor blockers MK-801 and AP-5 both NMDA receptor-operated ion channel blockers and the CNQX, a non-NMDA receptor blocker, were effective in delaying the development of increased $\mathrm{Ca}^{2+}$ after $\mathrm{MeHg}$ exposure [20]. In addition to glutamatergic receptors, there is evidence that voltage-dependent $\mathrm{Ca}^{2+}$ channels also contribute substantially to calcium influx after exposure to MeHg in neurons [20].

Regarding to a possible redox modulation of NMDA-type glutamate receptors directly by $\mathrm{MeHg}$, there are no available data in the literature. However, it is important to mention here the study of Tang and Aizenman [21] showing that the alkylation of the NMDA redox site by the sulfhydryl alkylating agent $\mathrm{N}$-ethylmaleimide (NEM) potentiated the response of receptor and renders NMDA receptors unresponsive to oxidation by Ellman's reagent 5,5' -dithiobis-(2-nitrobenzoic acid) (DTNB). Considering that the $\mathrm{MeHg}$ is a molecule as small as NEM and has high affinity by - $\mathrm{SH}$ groups, it is plausible to suppose that part of effects induced by $\mathrm{MeHg}$ on glutamate dyshomeostasis may be a consequence of its interaction with the redox modulatory site of the NMDA receptor. Taken together, the events mentioned above cause sustained elevation of intracellular $\mathrm{Ca}^{2+}$ that may trigger cell death pathways by many different mechanisms [20]. In these circumstances is pointed the close relationship existent between $\mathrm{Ca}^{2+}$ overload and mitochondria dysfunctions, which plays a crucial role in regulating cellular injury induced by $\mathrm{MeHg}$ (Figure 4). 

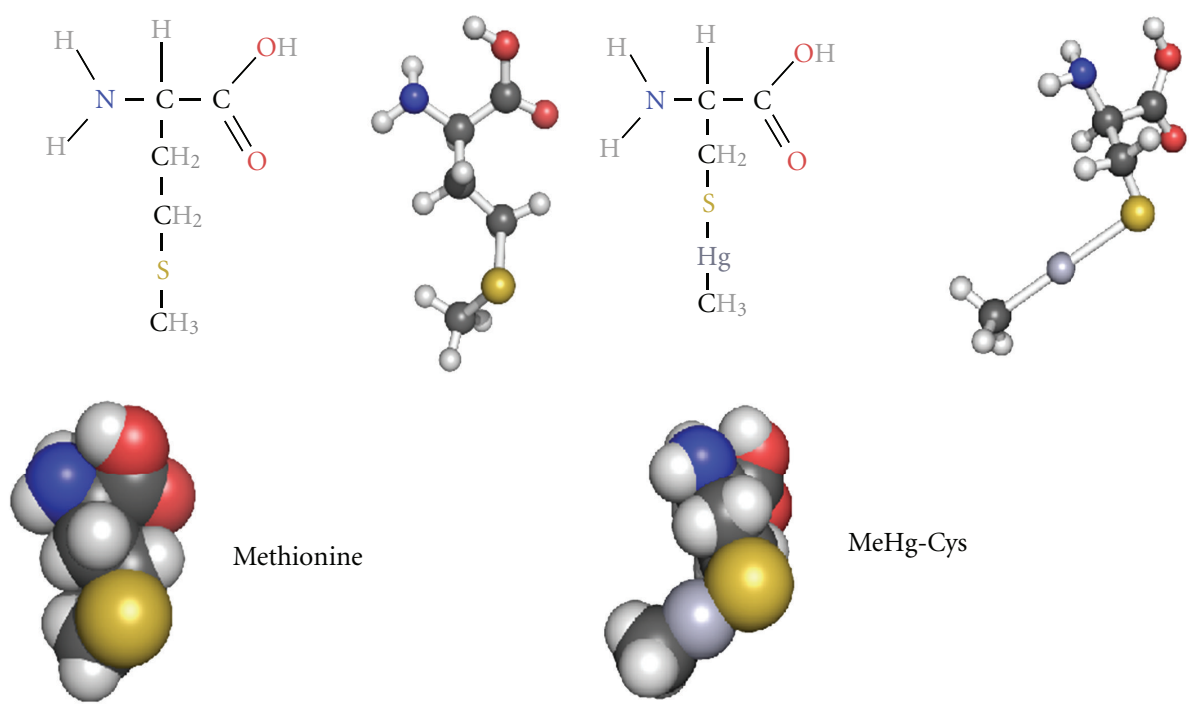

(a)

(b)

Figure 2: Schematic representation of the structures and space-filled models of methionine (a) and MeHg-Cys complex (b). Note the similarities in chemical structure between the MeHg-Cys conjugate and the amino acid methionine. The geometry-optimized using Universal Force Field (UFF). The representations (ball and stick, Vander Waals spheres) were obtained using the program PyMOL (Molecular Graphics System, Version 1.5.0.1, Schrödinger LLC).

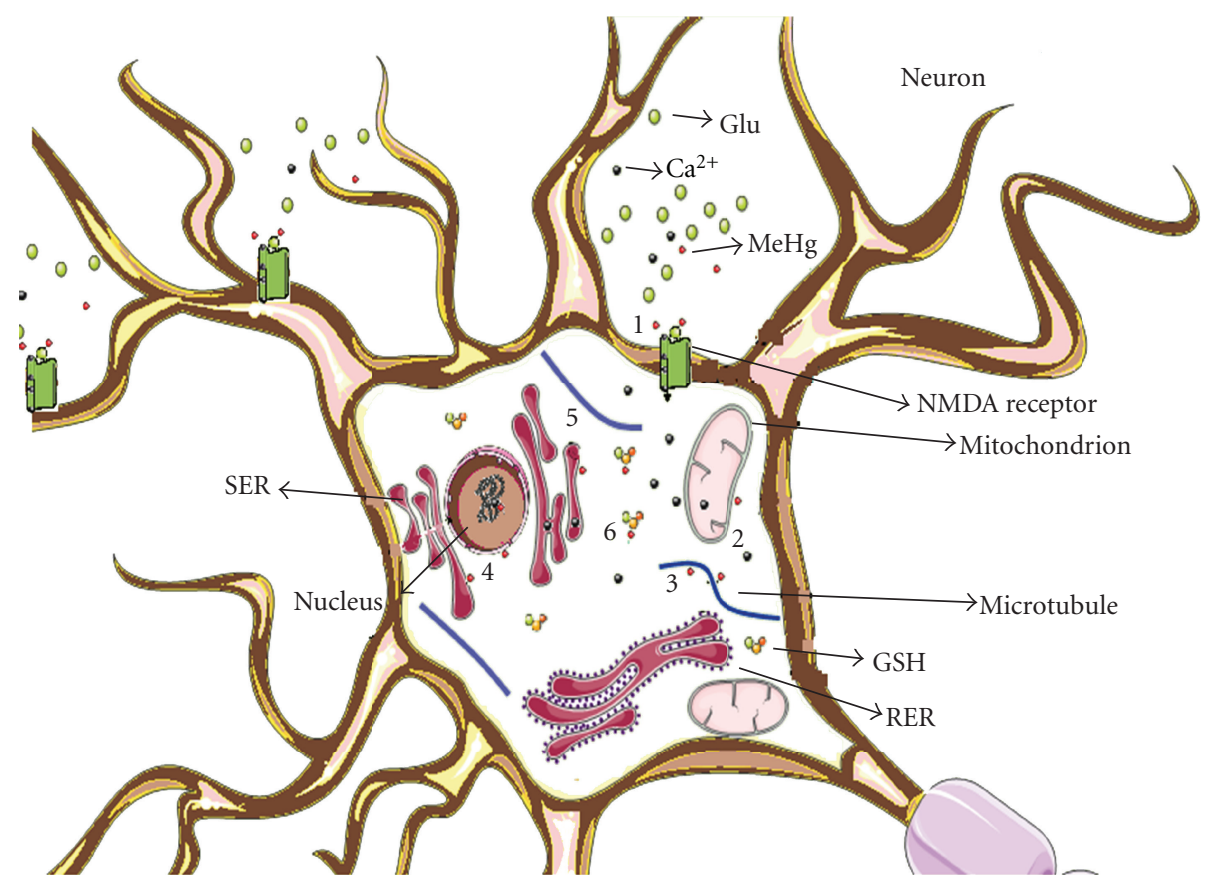

FIGURE 3: Schematic representation of possible mechanisms and cellular targets involved in the neurotoxicity MeHg-induced: (1) glutamate dyshomeostasis and $\mathrm{Ca}^{2+}$ intracellular dysregulation; (2) mitochondrial dysfunction; (3) cytoskeletal disruption; (4) DNA damage; (5) SER dysfunction; (6) thiol depletion (especially glutathione). This scheme is merely representative and the scale of structures does not represent the real size.

\section{Calcium Homeostasis and Mitochondria}

The concentration of $\mathrm{Ca}^{2+}$ in the cytosol is tightly regulated in all cells because calcium is a key element in metabolic and intracellular signaling regulation. Conversely, $\mathrm{Ca}^{2+}$ is also a relevant marker of numerous pathological processes when it is present at high, nonphysiological concentrations, notably neurological disorders [22]. The $\mathrm{Ca}^{2+}$ transport across neuronal cells membranes can occur by a variety of different mechanisms. In general, under resting conditions 


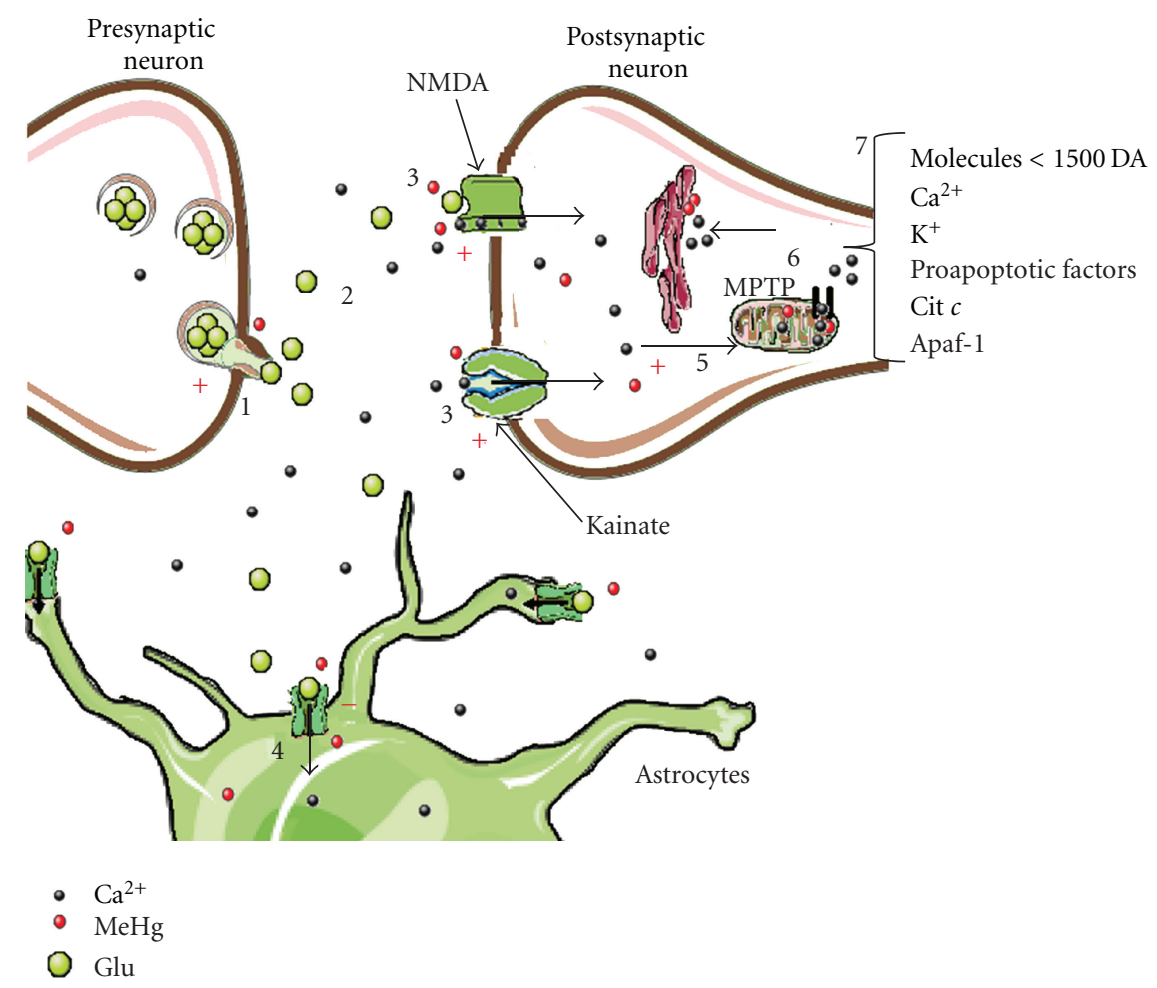

FIGURE 4: MeHg as mediator of neuronal toxicity via $\mathrm{Ca}^{2+}$-mediated excitotoxicity: (1) glutamate (Glu) release from presynaptic neuron induced by MeHg; (2) increase of Glu into synaptic cleft; (3) $\mathrm{Ca}^{2+}$ influx via NMDA and Kainate receptors; (4) MeHg binds at Glu transporters in astrocytes; (5) mitochondria buffering the excess of $\mathrm{Ca}^{2+}$ intracellular; (6) MeHg causing mitochondrial and SER damage; (7) MTPT opening with release of pro-apoptotic factors induced by $\mathrm{MeHg}$ alone and/or excess of $\left[\mathrm{Ca}^{2+}\right]_{m}$.

the intracellular $\mathrm{Ca}^{2+}$ levels $\left(\left[\mathrm{Ca}^{2+}\right]_{i}\right)$ are maintained at very low concentrations (in the $\mathrm{nM}$ range) when compared to the extracellular levels $\left(\left[\mathrm{Ca}^{2+}\right]_{e}\right)$ (in the $\mathrm{mM}$ range) $[20,22,23]$. On the order hand, in the region of transmitter release from active zones, at nerve terminals, the $\left[\mathrm{Ca}^{2+}\right]_{i}$ can be many times greater, reaching, at least transiently, $\mathrm{mM}$ levels [20, 23-29].

During normal neuronal activity the entry of $\mathrm{Ca}^{2+}$ into neurons occurs very fast and without energy expenditure, since it takes place in favor of the concentration gradient across the plasma membrane. However, the restoration of $\left[\mathrm{Ca}^{2+}\right]_{i}$ (following a transient increase) is much slower and depends on energy expenditure (either directly or indirectly through electrogenic "pumping" activities) $[23,25]$. Therefore, the restoration of $\left[\mathrm{Ca}^{2+}\right]_{i}$ homeostasis is extremely "expensive", being the "cost" directly proportional to the cell activity (i.e., highly active cells such as neurons expend a lot of cellular energy in order to restore the $\mathrm{Ca}^{2+}$ homeostasis). In this condition, some organelles can act as " $\mathrm{Ca}^{2+}$ buffers" by sequestering the excess of $\mathrm{Ca}^{2+}$; however, this "storage" of $\mathrm{Ca}^{2+}$ also requires cost of cellular ATP equivalents $[23,30,31]$ (Figure 5).

It is now well established that sustained elevations of $\left[\mathrm{Ca}^{2+}\right]_{i}$ can cause neuronal degeneration and cell death by activating biochemical cascades that result in either necrotic or apoptotic processes [30-39]. However, the exact molecular mechanisms by which continuous increases in
$\left[\mathrm{Ca}^{2+}\right]_{i}$ elicit neuronal cell death pathways are not fully understood. It is believed that these may include the activation of degradative enzymes, such as phospholipases, proteases and endonucleases, perturbation of cytoskeletal organization, and, primarily mitochondrial dysfunctions [22, 30,33].

Considering the importance of maintaining appropriate intracellular concentrations of $\mathrm{Ca}^{2+}$ for proper cellular function and the delicate balance between the physiological and toxicological effects of $\left[\mathrm{Ca}^{2+}\right]_{i}$, in addition to mechanisms for $\mathrm{Ca}^{2+}$ removal from the cell, there are also critic mechanisms for the intracellular storage of $\mathrm{Ca}^{2+}$ in the cells. The most important cellular $\mathrm{Ca}^{2+}$ stores are the organelles mitochondria and smooth endoplasmic reticulum (SER). Mitochondria present low affinity and high capacity to $\mathrm{Ca}^{2+}$, whereas the SER is a high-affinity and low-capacity $\mathrm{Ca}^{2+}$ pool [40]. So, while the SER moves $\mathrm{Ca}^{2+}$ from the cytosol into the SER lumen under low cytosolic $\left[\mathrm{Ca}^{2+}\right]_{i}$, the mitochondria requires a more powerful stimulus, being necessary a local extra-mitochondrial $\mathrm{Ca}^{2+}$ concentration of approximately $0.5 \mathrm{mM}$, for neuronal mitochondria to take up $\mathrm{Ca}^{2+}$ actively [31, 41-43] (Figure 5). Disruption of $\mathrm{Ca}^{2+}$ regulation in either of these stores can compromise the neuronal function and survival [44] (Figure 5).

With particular emphasis in mitochondria, it is well recognized that at physiological concentration, $\mathrm{Ca}^{2+}$ is a powerful regulator of organelle metabolic activity, which acts primarily promoting ATP synthesis by stimulating crucial 


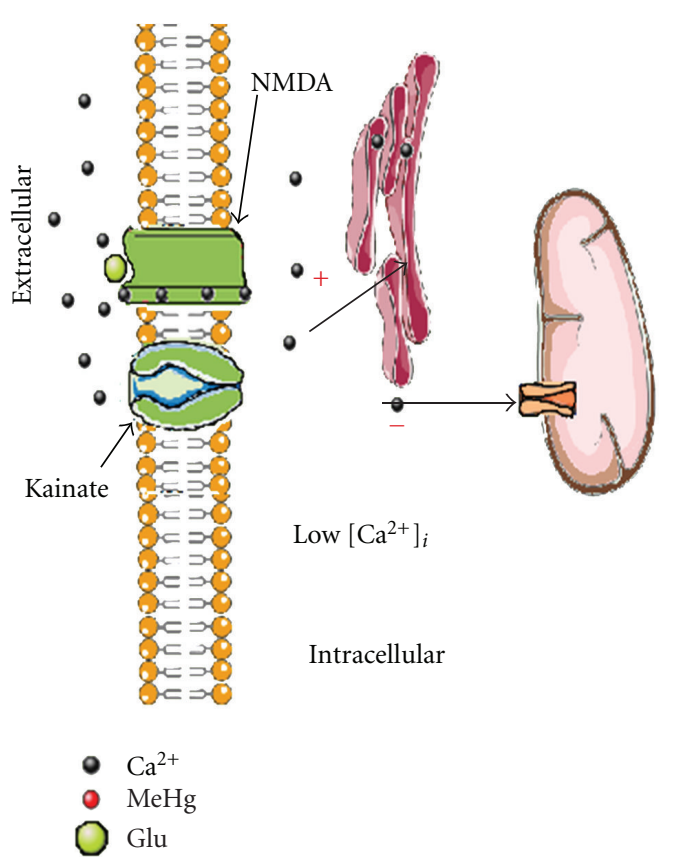

(a)

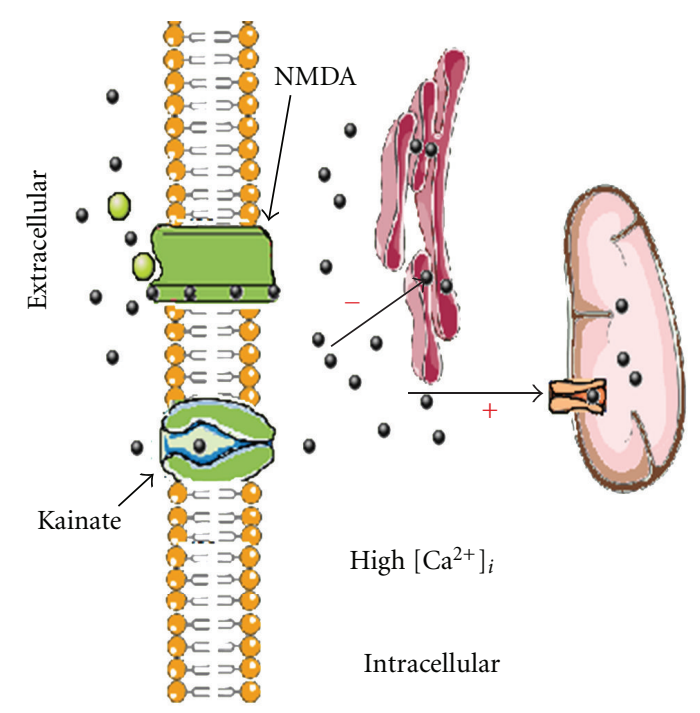
- $\mathrm{Ca}^{2+}$
- $\mathrm{MeHg}$
Glu

(b)

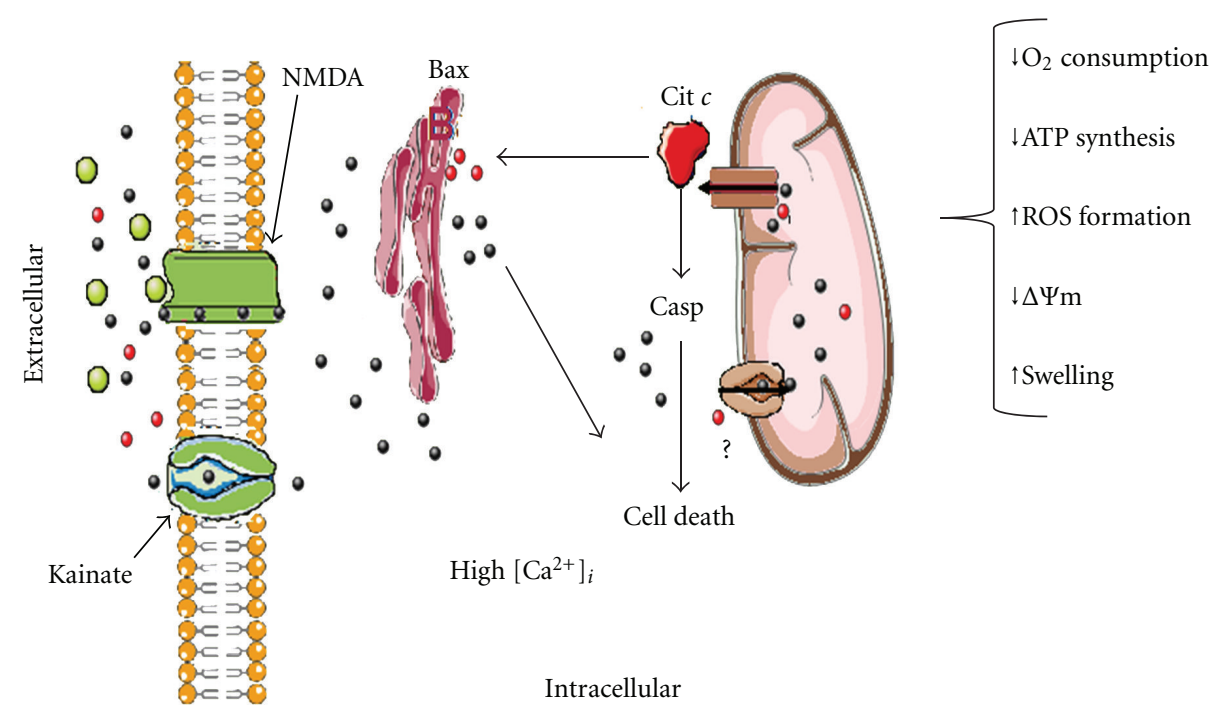

(c)

FIgURE 5: Schematic representation on the role of mitochondria and SER as intracellular $\mathrm{Ca}^{2+}$ stores and on the cellular death induced by $\mathrm{MeHg}$ via $\mathrm{Ca}^{2+}$ dyshomeostasis. (a) Under low cytosolic $\left[\mathrm{Ca}^{2+}\right]_{i}$ the SER preferentially moves $\mathrm{Ca}^{2+}$ from cytosol due its high affinity and low capacity to stores $\mathrm{Ca}^{2+}$; whereas (b) the mitochondria by presenting low affinity and high capacity to stores Ca ${ }^{2+}$ moves it under high cytosolic $\left[\mathrm{Ca}^{2+}\right]_{i}$; (c) the disruption of $\mathrm{Ca}^{2+}$ regulation produced by $\mathrm{MeHg}$ in either of these stores can lead to release of neuronal proapoptotic factors that may trigger cell death pathways. The scheme presented here is merely representative, and the scale of the different cellular structures does not represent the real size.

enzymes of Krebs cycle (pyruvate, ketoglutarate, and isocitrate dehydrogenases). On the order hand, mitochondrial changes that occur in most instances of cell death (apoptosis and necrosis) require an elevated influx of $\mathrm{Ca}^{2+}$ into matrix [30-38] (Figure 5).
It has been suggested that the outer membrane voltagedependent anion channel (VDAC), a ruthenium red (RuRed-) sensitive $\mathrm{Ca}^{2+}$ channel, serves to regulate $\mathrm{Ca}^{2+}$ entry to mito-chondrial intermembrane space (Figure 6). Furthermore, mitochondria take up a large quantity of 
$\mathrm{Ca}^{2+}$ across the inner membrane mainly via the activity of the mitochondrial calcium uniporter channel (MCU) [45] (Figure 6). This uptake is driven by the membrane potential $(\Delta \Psi m)$, and consequently the net movement of charge due to $\mathrm{Ca}^{2+}$ uptake collapses $\Delta \Psi m$ [45]. Although there is a general consensus that $\mathrm{MCU}$ is dominantly responsible for the $\mathrm{Ca}^{2+}$ influx into mitochondrial matrix, further studies have identified other pathways related to mitochondrial $\mathrm{Ca}^{2+}$ influx, including the mitochondrial ryanodine receptor (mRyR), mitochondrial uncoupling proteins, Letm1 $\left(\mathrm{Ca}^{2+} / \mathrm{H}^{+}\right.$antiporter $)$, and rapid mode of mitochondrial (RaM) [45] (Figure 6). It is also important to highlight here the ability of mitochondria in releasing $\mathrm{Ca}^{2+}$. Under normal physiological conditions, $\mathrm{Ca}^{2+}$ efflux from mitochondria is mediated primarily by mitochondrial $\mathrm{Na}^{+} / \mathrm{Ca}^{2+}$ exchanger. Indeed, $\mathrm{Ca}^{2+}$ efflux can also occur through uniporter channel if $\Delta \Psi m$ is collapsed. Interestingly, another $\mathrm{Ca}^{2+}$ efflux pathway is the classical mitochondrial permeability transition pore (MPTP), which is a large voltage-dependent channel formed by a set of mitochondrial proteins located in the inner membrane, mitochondrial matrix as well as on the outer membrane (Figure 6). Existing predominantly in the closed position, the pore transient opening under normal conditions may serve as a physiological means of releasing excess of metabolites, inorganic anions, and ions, especially $\mathrm{Ca}^{2+}[46-50]$. Indeed, MPTP permits the passage of several apoptotic mediators from mitochondria and is also a primary target of others, especially the Bcl-2 family proteins [51-55]. In this circumstances, it is important to emphasize the key role of mitochondrial $\mathrm{Ca}^{2+}$ overload and oxidative stress in MPTP opening.

There is a general conception that $\mathrm{Ca}^{2+}$ overload results in mitochondrial dysfunction, which trigger apoptosis by many different and connected pathways. In fact, a variety of molecular events involved in apoptotic stimulation focus on mitochondria. Mitochondrial changes as exacerbated ROS formation, dissipation of the $\Delta \Psi m$, altered redox potential, MPTP opening, release of apoptotic mediators (cytochrome c, Apaf-1 and apoptosis inducing factor (AIF)), and participation of proapoptotic $\mathrm{Bcl}-2$ family proteins are among the diverse signals associated to apoptosis induction by intrinsic or mitochondrial pathways $[16,51-55]$ (Figure 5). Indeed, ATP synthesis failure associated with mitochondrial dysfunctions can lead to abnormal cellular homeostasis causing swelling and cellular disruption, which eventually lead to necrotic death.

2.1. MeHg Disturbs Intracellular Calcium Homeostasis: Effects on Mitochondrial Function. A number of reports have indicated that $\mathrm{MeHg}$, at low micromolar concentrations, disrupts $\mathrm{Ca}^{2+}$ homeostasis and causes elevations in $\left[\mathrm{Ca}^{2+}\right]_{i}$ in different cells types, ranging from neurons and neuroblastoma cells to T lymphocytes and Purkinje cells [56-61]. The $\mathrm{Ca}^{2+}$ involvement on $\mathrm{MeHg}$ neurotoxicity is supported by several data, including the findings showing that the BAPTA $\left(\mathrm{a} \mathrm{Ca}^{2+}\right.$ chelator) is able to protect granule cells from $\mathrm{MeHg}$-induced mortality after short periods of exposure. The regulation of other divalent cations besides $\mathrm{Ca}^{2+}$, such as $\mathrm{Zn}^{2+}$ may be also

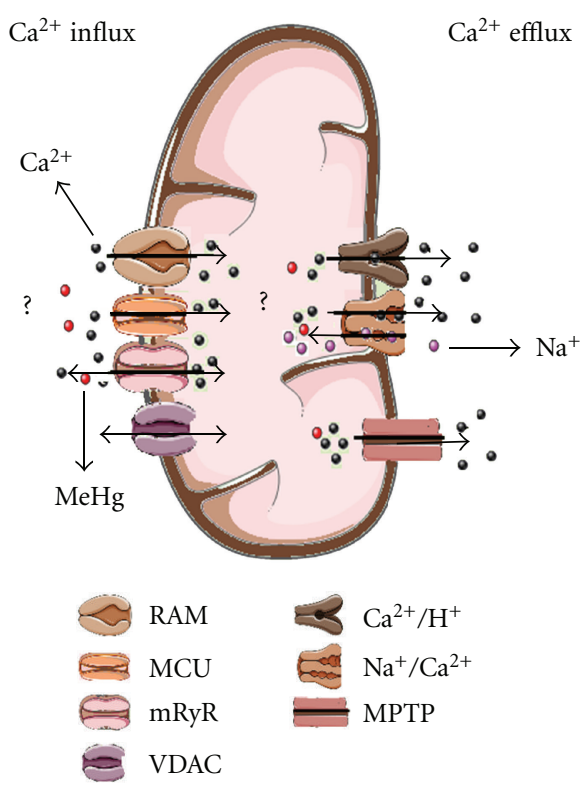

FIGURE 6: Representation of different channels responsible for $\mathrm{Ca}^{2+}$ influx/efflux in mitochondria and the possible interaction of $\mathrm{MeHg}$ with these channels. VDAC: outer membrane voltagedependent anion channel; RAM: rapid uptake model; MCU: inner membrane calcium uniporter channel; mRyR: mitochondrial ryanodine receptor; $\mathrm{Ca}^{2+} / \mathrm{H}^{+}$antiporter; $\mathrm{Na}^{+} / \mathrm{Ca}^{2+}$ exchanger; MPTP: mitochondrial permeability transition pore. The scale of structures represented in this scheme does not represent the real size.

disrupted during $\mathrm{MeHg}$ exposure; nevertheless, here we will focus on the effect of $\mathrm{MeHg}$ in $\mathrm{Ca}^{2+}$ homeostasis [62].

As previously mentioned, it has been postulated that the effects of $\mathrm{MeHg}$ on neuronal $\mathrm{Ca}^{2+}$ homeostasis, at least in part, involve the excitatory amino acids receptors (either NMDA and non-NMDA receptors), since that channel blockers as $\omega$-conotoxin GVIA and nifedipine delay MeHg-induced elevation in $\left[\mathrm{Ca}^{2+}\right]_{i}$ levels $[19,20]$. In accordance, several studies have demonstrated that the glutamate overactivation of NMDA receptor induced by $\mathrm{MeHg}$ inhibtion of glutamate uptake can raise intracellular $\mathrm{Ca}^{2+}$ influx and ROS overproduction [16]. In addition, experimental evidence also supports the participation of $\mathrm{L}$ and $\mathrm{N}$-type $\mathrm{Ca}^{2+}$ channels on $\mathrm{MeHg}$ neurotoxicity given that blockers of voltage-dependent $\mathrm{Ca}^{2+}$ channels prevent the appearance of neurological disorders in rats exposed to $\mathrm{MeHg}[63,64]$. In this sense, a recent work suggested that canonical transient receptor potential channels (TRPC), $\mathrm{Ca}^{2+}$-permeable cationic channels, could be important for the mechanisms of cytotoxicity and neuronal impairment mediated by MeHg. In fact, in this study was observed that $\mathrm{MeHg}$ that potently activates TRPC5 as well as TRPC4 channels via binding to the two extracellular cysteine residues near the channel pore, whereas silence of TRPC5 gene with small interfering RNA (siRNA) or blockade of TRPC channel activity with pharmacological tools alleviates MeHgrelated cytotoxicity [65]. Notwithstanding, some findings have shown that $\mathrm{MeHg}$ toxicity may be triggered by elevating $\left[\mathrm{Ca}^{2+}\right]_{i}$ through activation of phosphatidylcholinespecific phospholipase C (PC-PLC), which could contribute 
to the entry of extracellular $\mathrm{Ca}^{2+}$ as well as to the opening of transmembrane $\mathrm{Ca}^{2+}$ channels from intracellular $\mathrm{Ca}^{2+}$ store $[66,67]$.

Numerous lines of evidence indicate that the MeHgmediated neuronal cells death is associated with a severe loss of $\left[\mathrm{Ca}^{2+}\right]_{i}$ homeostasis $[58,59,68]$. In neurons and NG108-15 neuroblastoma cells, MeHg causes a characteristic biphasic increase in $\left[\mathrm{Ca}^{2+}\right]_{i}$ that consists of an initial release of $\mathrm{Ca}^{2+}$ from one or more intracellular stores into the cytosol ("first-phase"), and a secondary influx of $\left[\mathrm{Ca}^{2+}\right]_{e}$ ("secondphase") [56, 58]. However, it is necessary to consider that the elevation of $\left[\mathrm{Ca}^{2+}\right]_{i}$ occurs at much lower $\mathrm{MeHg}$ concentrations in cerebellar granule cells than in NG10815 cells, which could explain, at least in part, the different sensitivity of granule cells to the toxic effects of $\mathrm{MeHg}$ as compared to other neuronal cells $[56,58]$. In analogy, there is evidence that elevated $\left[\mathrm{Ca}^{2+}\right]_{i}$ has a important role in dimethylmercury (di-MeHg-) induced cell death. Of note, $\mathrm{Ca}^{2+}$ deposits (as calcospherites, a spherical mass of calcium salts and organic matter) were found in cerebellar slices of rats treated with di-MeHg. The cerebellar accumulation of calcospherites was directly proportional to exposure time, and the atrophy of the granule cell layer was evident at later time points [69]. Moreover, it has been observed that adjacent Purkinje cells did not show any sign of cell loss or death, nor accumulate $\mathrm{Ca}^{2+}$ [69]. These findings suggest that the presence or absence of $\mathrm{Ca}^{2+}$ deposits within the cerebellum seems to be directly correlated with sensitivity or resistance of cells to $\mathrm{MeHg}$ neurotoxicity. Noteworthy, it is important to mention here that this study was done with di-MeHg which is much more toxic to humans than mono-MeHg [68]. This is important to avoid confusion between mono- $\mathrm{MeHg}$ and di-MeHg, particularly in view of the extreme toxicological effects of di-MeHg to humans (even at low concentrations). Other important critical aspect here is the involvement of cerebellum in $\mathrm{MeHg}$ toxicity. Although this seems to be the case for humans (and cats), it is difficult to find in rodent literature "a clear picture" that mono-MeHg targets preferentially cerebellum than other brain structure. It is possible that cerebellum of rats be more sensitive to di-MeHg, which has been little used (possibly because of its chemical instability and toxicity).

Important early studies by Yoshino et al. [70] showed that $\mathrm{MeHg}$ is able to accumulate rapidly in mitochondria. In this way, subsequent works indicated a spectrum of mitochondrial effects, either directly or indirectly via $\mathrm{Ca}^{2+}$ overload, of $\mathrm{MeHg}$ both in vivo and in vitro, including alterations in complex III of the mitochondrial electron transport chain (ETC), depression of respiration and ATP production, swelling of the mitochondrial matrix, and loss of $\Delta \Psi m$ with subsequent release of cytochrome c [71-80]. The loss of $\Delta \Psi m$ seems to result from MPTP opening, which can be prevented by treatment with the pore-blocking agent cyclosporin A (CsA) or bongkrekic acid [81-84]. In several studies CsA, but not FK506, that is similar to CsA but without MPTP inhibitory activity, provides a marked degree of neuroprotection against $\mathrm{MeHg}$, supporting the involvement of MPTP in the MeHg neurotoxicity [73, 85-87]. Other experimental evidence shows that mitochondria contributes to the MeHg-induced first-phase $\left[\mathrm{Ca}^{2+}\right]_{i}$ increase and subsequent cell death through opening of the MPTP [56].

To note, mitochondria have been considered the principal source of intracellular $\mathrm{Ca}^{2+}$ release in culture of cerebellar granule cells during $\mathrm{MeHg}$ exposure [73]. It has been documented that $\mathrm{MeHg}$ affects mitochondrial $\mathrm{Ca}^{2+}\left(\left[\mathrm{Ca}^{2+}\right]_{m}\right)$ regulation through at least two potential mechanisms. The first involves its direct interaction with mitochondrial proteins, which is thought to alter the ability of mitochondria in functioning normally. Corroborating this idea, there is evidence that $\mathrm{MeHg}$ inhibits mitochondrial nucleic acid synthesis and interferes with the electron transport chain via direct interaction with respiratory proteins [79] as well as causes loss of inner mitochondrial membrane potential in isolated mitochondria from different tissues, including neuronal cells $[48,71,73,85,88,89]$. The second mechanism is associated with an indirect inhibition of mitochondrial function via excessive uptake of $\mathrm{Ca}^{2+}$ into the mitochondria. The elevated $\left[\mathrm{Ca}^{2+}\right]_{m}$ may depolarize the inner mitochondrial membrane, inhibit the tricarboxylic acid cycle and the mitochondrial ATPase, dissipate the mitochondrial proton gradient, and promote MPTP opening [8894]. Of particular importance, $\left[\mathrm{Ca}^{2+}\right]_{m}$ can be increased after $\mathrm{Ca}^{2+}$ release from SER. Experiments in NG108-15 neuroblastoma cells and cerebellar granule cells show that $\mathrm{MeHg}$ causes $\mathrm{Ca}^{2+}$ release from SER, primarily through IP3 receptor, which is buffered by mitochondria (tentatively to maintain $\left[\mathrm{Ca}^{2+}\right]_{i}$ homeostasis) $[95,96]$. Corroborating these findings, an elegant study performed by Budd and Nicholls [97] demonstrated that mitochondria can store and release large amounts of $\mathrm{Ca}^{2+}$ under both physiological and pathological conditions in granule neurons [96-98]. Taken together, these data suggest that the excessive uptake of $\left[\mathrm{Ca}^{2+}\right]_{m}$ after release of $\mathrm{Ca}^{2+}$ from the SER is a potential signal for the MPTP opening and $\left[\mathrm{Ca}^{2+}\right]_{m}$ release from the mitochondrial lumen into the cytosol in cerebellar granule cells exposed to $\mathrm{MeHg}$. These observations are also consistent with the hypothesis that both $\mathrm{Ca}^{2+}$ ionophore A23187 and $\mathrm{MeHg}$ cause a rapid and massive increase in mitochondrial $\mathrm{Ca}^{2+}$ influx, which secondarily triggers the overproduction of ROS that facilitates MPTP induction, loss of the electron transport chain activity, and the ensuing mitochondrial death [98]. Thus, an uncontrolled release of $\mathrm{Ca}^{2+}$ from the mitochondria may occur during oxidative stress, a condition resulting from the imbalance between the production of free radicals and the counteraction by the cellular antioxidant defenses $[49,99]$.

Based on the evidence addressed previously, mitochondria must be considered critical in the regulation of neuronal cell death induced by $\mathrm{MeHg}$ via $\mathrm{Ca}^{2+}$ dyshomeostasis and/or ROS generation (under oxidative stress conditions) [48-50]. In this sense, literature data have pointed that ROS formation is not the cause of mitochondrial dysregulations after $\mathrm{MeHg}$ exposure but rather a secondary event that reflects $\mathrm{MeHg}$ induced elevations in mitochondrial $\mathrm{Ca}^{2+}$ levels $[48,53]$. In agreement, an in vitro study revealed that the treatment of striatal synaptosomes with the antioxidant Trolox was effective in reducing ROS levels but failed on restoring mitochondrial damage induced by $\mathrm{MeHg}$ [100]. Similarly, 
in a recent work using rat cortical slices was evidenced that the flavonoids quercitrin and quercetin reduced significantly mitochondria MeHg-generated ROS production, which was dependent upon an increase in intracellular $\mathrm{Ca}^{2+}$ levels [74, $101]$.

2.2. MeHg-Induced ROS Formation and Mitochondrial Dysfunction: Effect of Antioxidants. As already cited before, mitochondrial dysfunctions elicited by $\mathrm{MeHg}$ may lead to a mitochondrial burst of ROS production. ROS are important mediators of damage to cell structures, including lipids and membranes, as well as proteins and nucleic acids [102, 103]. In mitochondria, ROS may impair energy metabolism by inducing oxidative structural changes and the ensuing loss of activity in a number of mitochondrial enzymes that play critical roles in ATP production [42]. Besides, the direct action of ROS on mitochondrial membrane lipids and proteins results in the activation of apoptotic cascades by MPTP opening dependent or independent mechanisms $[51,53,54]$.

The detrimental effects of ROS are balanced by the antioxidant action of nonenzymatic and enzymatic systems [104]. Indeed to ROS overproduction, in vivo and in vitro experimental observations have shown that the toxic effects of $\mathrm{MeHg}$ usually are accompanied by significant deficits in antioxidant defenses. MeHg can cause a decrease in the endogenous nonenzymatic antioxidants as well as an inhibition of the antioxidant enzymes [104-110]. Thus, it is reasonable to suppose that the cellular/mitochondrial ROS production may be directly or indirectly triggered by $\mathrm{MeHg}$. In fact, the high affinity of $\mathrm{MeHg}$ by $-\mathrm{SH}$ groups might decrease GSH content and consequently facilitates ROS formation [11]. On the order hand, $\mathrm{MeHg}$ also could exacerbate ROS formation by increasing $\left[\mathrm{Ca}^{2+}\right]_{i}$. From a molecular point of view, as highlighted in Figure 7, these factors (GSH depletion, ROS and $\mathrm{Ca}^{2+}$ ) exist as a pyramidal network, where they may act independently or through a complex interaction to activate the cascade of events involved in cell injury mediated by $\mathrm{MeHg}$. With this in mind, the following sections discuss two possible antioxidant therapies (natural and synthetic) that could be effective in ameliorating the symptoms of $\mathrm{MeHg}$ intoxication by interfering with these factors.

2.2.1. Natural Antioxidants against MeHg-Induced Toxicity. Despite the massive efforts in the search for new drugs that counteract mercurial toxicity, there are no effective treatments available that completely abolish its toxic effects. In general, the available antidotal strategies to treat mercury poisonings are largely based on chelating therapies. The use of sulfhydryl-enriched chelators is based on the high affinity of $\mathrm{MeHg}$ to $-\mathrm{SH}$ groups, leading to mercury elimination from tissues predominantly via renal excretion. However, these drugs are of limited use, because of their adverse side effects [111]. Moreover, it has been proposed that chelating therapies are ineffective in poisonings with organic forms of mercury [112], although this issue remains controversial [113, 114]. Nevertheless, there is general agreement that metal chelators are unable to completely

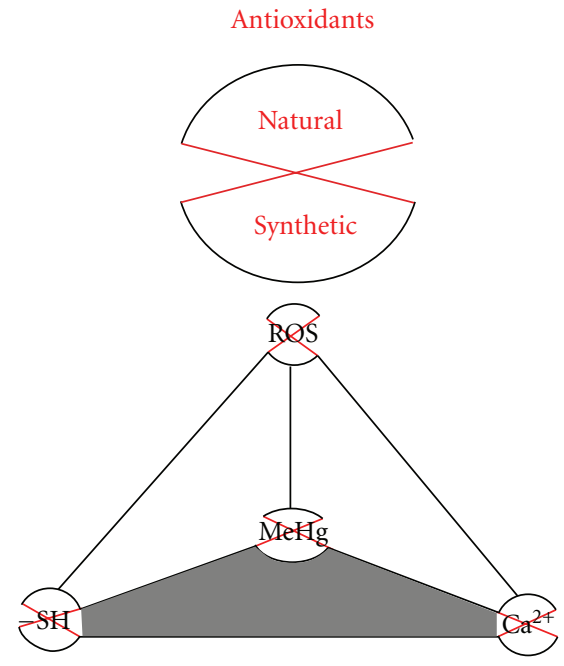

Figure 7: Pyramidal network involved in MeHg neurotoxicity: Arrows denote the interlinked possible pathways by which $\mathrm{MeHg}$ may cause cellular damage and the protective effect of natural and synthetic antioxidants against $\mathrm{MeHg}$ neurotoxicity by blocking oxidative events triggered via -SH depletion, ROS formation, and $\mathrm{Ca}^{2+}$ dyshomeostasis. For full details, see the text.

eliminate mercurials' body burden and by inference, toxicity. Thus, the use of compounds with antioxidant properties and no apparent side effects could represent an efficient coadjuvant strategy to counteract $\mathrm{MeHg}$ toxicity. Therefore, various purified phytochemicals or plant extracts have been shown to confer some protection against $\mathrm{MeHg}$-mediated excitotoxicity and oxidative stress in vivo and in vitro [106, 115]. Possible mechanisms involved in the mitigation of $\mathrm{MeHg}$ effects by phytochemicals may include the reduction of ROS production, activation of enzymatic antioxidant systems, restoration of the mitochondrial membrane potential, and modulation of cell signaling pathways [116]. Dietary phytochemicals may also affect additional endpoints such as $\mathrm{MeHg}$ bioavailability and pharmacokinetics [117, 118]. In particular, natural products (such as flavonoids) whose antioxidant properties have been well described [119-121] could represent important therapeutic choices. In this sense, it has been characterized in both in vitro and in vivo experimental models that flavonoids exert beneficial effects by preventing or reducing free radical production, blocking $\mathrm{Ca}^{2+}$ influx into cells, chelating iron, and exerting antiinflammatory action [100, 121, 122] (Figure 7). Indeed, such class of compounds has displayed neuroprotective effects in several experimental models of neurodegeneration [123125]. Of particular significance, the current literature shows that plant extracts containing flavonoid provide protection against $\mathrm{MeHg}$-induced neurotoxicity in mice [115, 121]. The protective effect of flavonoids has been correlated with their capacity in detoxifying the $\mathrm{H}_{2} \mathrm{O}_{2}$ generated in the presence of mercurials [71]. In addition to a direct interaction with $\mathrm{H}_{2} \mathrm{O}_{2}$, it is possible that flavonoids may also reduce $\mathrm{H}_{2} \mathrm{O}_{2}$ production via inhibition of $\mathrm{Ca}^{2+}$ influx into cells or mitochondria [105] and/or by forming redox inactive complexes with iron, rendering this prooxidant unavailable for Fenton reaction. 
A recent in vitro study using the flavonoids quercetin, rutin, and quercitrin showed that lipid peroxidation and ROS generation in both mitochondria-enriched fractions and cortical brain slices exposed to $\mathrm{MeHg}$ were significantly reduced by quercetin and quercitrin [74]. Likewise, further findings demonstrated that mangiferin was effective in offering protection to human neuroblastoma cells against the toxic effects of MeHg. The protective effect of this flavonoid was attributed to its antigenotoxic, antiapoptotic and antilipid peroxidative potential plausibly because of its free radical scavenging ability, which reduced the oxidative stress and in turn facilitated the downregulation of mitochondrial apoptotic signalling pathways [126-128]. Corroborating these experimental observations, a current study performed by Franco et al. showed that the flavonoids myricetin, myricitrin, and rutin are able in reducing mitochondrial dysfunctions in mouse brain mitochondrialenriched fractions treated with $\mathrm{MeHg}$ in vitro; being that the myricetin displayed higher protective effect against $\mathrm{MeHg}$-induced mitochondrial toxicity when compared to myricitrin and rutin [129]. Additionally, only the myricetin was able to inhibit completely ROS formation and lipid peroxidation $\mathrm{MeHg}$ induced [129]. The scavenger property of this flavonoid was considered, at least in part, responsible for its protective effects against mitochondrial dysfunction induced by $\mathrm{MeHg}$.

From a molecular point of view, the antioxidant activities of flavonoids can be influenced by their chemical structure $[130,131]$, and there are several molecular characteristics that confer the ability of a given flavonoid to promptly donate electrons and reduce reactive species. Basically, polyphenolic flavonoids possess a diphenylpropane (C6C3C6) skeleton $[130,131]$. The presence of hydroxyl groups linked to phenolic rings correlates with their capability to donate electrons [132]. The positions and, more importantly, the amounts of hydroxyl groups present in the polyphenolic skeleton increase their ability to neutralize reactive species $[130,131]$. The removal of this functional group from flavonoids has been reported to impair their antioxidant potency [130-132]. Lack of saturation at the C-ring is another structural property that confers antioxidant ability to flavonoids. Similarly, the blockade of the hydroxyl group in the C-ring through glycosylation has also been reported to decrease the antioxidant ability of this class of compounds [130-133].

Despite the potential use of natural products (specially flavonoids) to counteract the MeHg-induced cell damage via mitochondria-mediated ROS generation, more in vivo experiments are needed to validate the efficacy of flavonoids in attenuating $\mathrm{MeHg}$-mediated injuries, particularly in view of the recently published synergistic neurotoxic action of quercetin and $\mathrm{MeHg}$ in adult mice [101].

\subsection{Synthetic Antioxidants against MeHg-Induced Toxicity.} Similar to natural compounds, numerous synthetic compounds exhibit potent antioxidant properties that could be effective in reducing the oxidative damage elicited by $\mathrm{MeHg}$. However, the focus of this section will be in some selenium (Se) compounds, since it has long been hypothesized that

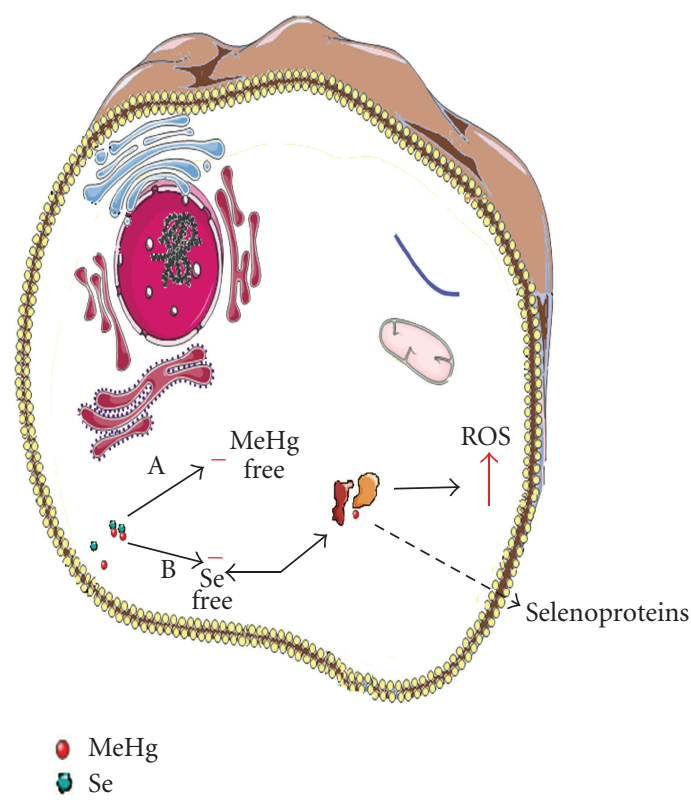

FIgure 8: Possible role of Selenium (Se) on MeHg toxicity: (A) $\mathrm{MeHg}$ toxicity reduced by formation of complex MeHg-Se; (B) $\mathrm{MeHg}$ toxicity increased due Se depletion by formation of complex MeHg-Se: $\downarrow$ Selenoprotein activities and synthesis and $\uparrow$ ROS.

Se may protect against the harmful effects of mercury, particularly organic $\mathrm{MeHg}$ [134].

Most of beneficial effects exhibited by Se in biological systems are connected to activity of enzymes glutathione peroxidases family (GPx1-4), thioredoxin reductase family (TrxR1-2), thioredoxin glutathione reductase (TGR), and iodothyronine deiodinase isoforms (DIO1-3), which present this element as a structural component [135].

Regarding to mercury toxicity, it has been pointed that the strong interaction between mercury and Se is an important mechanism related to neuroprotection offered by selenium compounds $[135,136]$ (Figure 8). From this point of view, the Se's protective role is associated with the formation of stable complex(es) resulting of the reaction between mercurials and selonohydryl/selenol groups $(-\mathrm{SeH})$ formed from de selenium compounds. However, it is important to mention here that little is known about the toxicokinetics of these complexes in biological systems. Furthermore, some studies argue that Se sequestration due to mercury binding to Se could compromise Se's biological functions and availability, mainly by impairing selenoenzyme activities and synthesis [135] (Figure 8).

The use of synthetic compounds containing selenium has received growing interest as therapeutic strategies in the treatment of mercury intoxication symptoms, including the detrimental effects of $\mathrm{MeHg}$ in CNS [135-137]. Of particular importance are the GPx- and TRxR-like activities displayed by ebselen and diphenyl diselenide, two simple synthetic organoselenium compounds that have been considered potent antioxidant and neuroprotective agents in different experimental models $[136,138]$. Current literature findings show that these compounds may be reduced by mammalian 
(TrxR) forming selenolate intermediates that are potent nucleophiles and can readily react with electrophilic species, including ROS [138]. This implies that these compounds could efficiently attenuate the oxidative damage caused by $\mathrm{MeHg}$. Corroborating this hypothesis, a recent study revealed that diphenyl diselenide reduced cerebral oxidative stress as well as $\mathrm{Hg}$ deposition in the liver, kidneys, and brain of adult mice exposed to $\mathrm{MeHg}$ [13]. In this work the authors assume that the effectiveness exhibited by compound is derived from the formation of a stable complex (MeHg-Selenol) due interaction of $\mathrm{MeHg}$ with a "selenol intermediate" [13].

Based on the observations previously cited, it is reasonable to suppose that ebselen and diphenyl diselenide might diminish the neurotoxic action of $\mathrm{MeHg}$ by increasing the excretion of $\mathrm{MeHg}$ from the body due their abilities in forming inert complexes with $\mathrm{MeHg}$ [13]. Regarding to the involvement of glutamatergic system on $\mathrm{MeHg}$ neurotoxicity, there is in vitro evidence that both organoselenium compounds as well as MK-801 were effective on blocking ROS formation caused by $\mathrm{MeHg}$ in cortical rat brain slices by maintaining the hydrogen peroxide status at low physiological levels and/or through a direct modulation of the NMDA receptor redox site [110]. Likewise, the treatment of cerebral cortex slices from young rats with ebselen restored the glutamate uptake and cell viability changed by $\mathrm{MeHg}$ exposure [139]. Differently, in this experimental protocol diphenyl diselenide did not modify these parameters [139].

In addition, data from ex vivo experiments show that glutamate release from brain synaptosomal preparations and glutamate uptake by brain cortical slices is increased in rat pups exposed to $\mathrm{MeHg}$ during the suckling period and that these effects were prevented by ebselen [140]. Equally important, there is evidence that ebselen was effective in reversing the inhibition induced by oral exposure to $\mathrm{MeHg}$ on glutamate uptake of brain cortical slices of adult mice as well as in restoring the activity of enzymes glutathione peroxidase and catalase activity, which were modified by $\mathrm{MeHg}$. These protective effects of ebselen were related to its ability to detoxify $\mathrm{H}_{2} \mathrm{O}_{2}$ [140].

Of particular importance, recently an elegant study demonstrated the potential ability of ebselen and diphenyl diselenide in preventing neuronal dysfunction caused by $\mathrm{MeHg}$ via cytoskeletal proteins disruption. In this work $\mathrm{MeHg}$ exposure induced hyperphosphorylation of the high molecular weight neurofilaments subunit from slices of cerebral cortex of young rats, and both selenium compounds ebselen and diphenyl diselenide were efficient in reversing these alterations [141].

As stated before, there is numerous experimental evidence suggesting that $\mathrm{MeHg}$ exposure may induce damage in mitochondria from different organs and tissue [74], and that this effect could be associated to ROS overproduction and/or increased intracellular calcium levels [74, 142]. However, to the best of our knowledge, there are no reports on the role of organoselenium compounds in isolated mitochondria challenged by $\mathrm{MeHg}$. Thus, although the organic selenium forms cited here may represent an interesting class of compounds as therapeutic agents against $\mathrm{MeHg}$ intoxication, further research to evaluate the efficacy and safety of such compounds will be needed.

\section{Conclusion}

Despite the large number of studies on $\mathrm{MeHg}$ toxicity, the understanding about the metabolism and toxicokinetics of $\mathrm{MeHg}$ as well as the molecular mechanisms involved in its neurotoxic effects remains to be fully elucidated. Meanwhile, taken together the data discussed in this paper collaborate for a better understanding of the multifactorial mechanisms (glutamate and calcium dyshomeostasis, as well as mitochondrial dysfunction) involved on neurotoxicity produced by $\mathrm{MeHg}$ and point the possible interlinked pathways by which $\mathrm{MeHg}$ might cause neuronal damage, with special emphasis on mitochondrial disturbances, since the mitochondria seem to be a key organelle implicated in the detrimental effects triggered by $\mathrm{MeHg}$ both in vivo and in vitro. In this regard, experimental studies show that both synthetic and natural antioxidants may be considered promising molecules in counteracting the toxic effects elicited by MeHg. Thus, although experimental research has been highly instrumental in shedding novel information on aspects involved in MeHg-induced neurotoxicity, further studies on the precise temporal relationship between the listed phenomena, as well as potential therapeutic/antidotal strategies to counteract the mitochondrial dysfunction produced by $\mathrm{MeHg}$ are warranted.

\section{Acknowledgments}

The authors would like to thank the colleagues/coauthors who contributed to several studies referenced in this paper. The financial support by FINEP Research Grant "Rede Instituto Brasileiro de Neurociência (IBN-Net)" no. 01.06.084200, FAPERGS/Pronex, CAPES/SAUX, CAPES/NOVOS TALENTOS, VITAE Fundation, INCT-CNPq-Excitotoxicity and Neuroprotection, and $\mathrm{CNPq}$ is gratefully acknowledged. Nilda Vargas Barbosa is the recipient of CNPq fellowships.

\section{References}

[1] T. W. Clarkson, "The three modern faces of mercury," Environmental Health Perspectives, vol. 110, no. 1, pp. 11-23, 2002.

[2] R. A. Bernhoft, "Mercury toxicity and treatment: a review of the literature," Journal of Environmental and Public Health, vol. 2012, Article ID 460508, 10 pages, 2012.

[3] E. Oken and D. C. Bellinger, "Fish consumption, methylmercury and child neurodevelopment," Current Opinion in Pediatrics, vol. 20, no. 2, pp. 178-183, 2008.

[4] G. J. Myers, S. W. Thurston, A. T. Pearson et al., "Postnatal exposure to methyl mercury from fish consumption: a review and new data from the Seychelles Child Development Study," NeuroToxicology, vol. 30, no. 3, pp. 338-349, 2009.

[5] F. Bakir, S. F. Damluji, and I. Amin Zaki, "Methylmercury poisoning in Iraq: an interuniversity report," Science, vol. 181, no. 4096, pp. 230-241, 1973.

[6] M. Harada, "Congenital Minamata disease: intrauterine methylmercury poisoning," Teratology, vol. 18, no. 2, pp. 285-288, 1978. 
[7] A. Spurgeon, "Prenatal methylmercury exposure and developmental outcomes: review of the evidence and discussion of future directions," Environmental Health Perspectives, vol. 114, no. 2, pp. 307-312, 2006.

[8] S. Bose-O'Reilly, K. M. McCarty, N. Steckling, and B. Lettmeier, "Mercury exposure and children's health," Current Problems in Pediatric and Adolescent Health Care, vol. 40, no. 8, pp. 186-215, 2010.

[9] J. Stringari, A. K. C. Nunes, J. L. Franco et al., "Prenatal methylmercury exposure hampers glutathione antioxidant system ontogenesis and causes long-lasting oxidative stress in the mouse brain," Toxicology and Applied Pharmacology, vol. 227, no. 1, pp. 147-154, 2008.

[10] A. Dreiem, C. C. Gertz, and R. F. Seegal, "The effects of methylmercury on mitochondrial function and reactive oxygen species formation in rat striatal synaptosomes are agedependent," Toxicological Sciences, vol. 87, no. 1, pp. 156-162, 2005.

[11] Z. Yin, H. Jiang, T. Syversen, J. B. T. Rocha, M. Farina, and M. Aschner, "The methylmercury-L-cysteine conjugate is a substrate for the L-type large neutral amino acid transporter," Journal of Neurochemistry, vol. 107, no. 4, pp. 1083-1090, 2008.

[12] N. Ballatori, "Transport of toxic metals by molecular mimicry," Environmental Health Perspectives, vol. 110, no. 5, pp. 689-694, 2002.

[13] D. H. Roos, R. L. Puntel, T. H. Lugokenski et al., "Complex methylmercury-cysteine alters mercury accumulation in different tissues of mice," Basic and Clinical Pharmacology and Toxicology, vol. 107, no. 4, pp. 789-792, 2010.

[14] D. H. Roos, R. L. Puntel, M. Farina et al., "Modulation of methylmercury uptake by methionine: prevention of mitochondrial dysfunction in rat liver slices by a mimicry mechanism," Toxicology and Applied Pharmacology, vol. 252, no. 1, pp. 28-35, 2011.

[15] M. Aschner, T. Syversen, D. O. Souza, J. B. T. Rocha, and M. Farina, "Involvement of glutamate and reactive oxygen species in methylmercury neurotoxicity," Brazilian Journal of Medical and Biological Research, vol. 40, no. 3, pp. 285-291, 2007.

[16] M. Farina, M. Aschner, and J. B. T. Rocha, "Oxidative stress in MeHg-induced neurotoxicity," Toxicology and Applied Pharmacology, vol. 256, no. 3, pp. 405-417, 2011.

[17] G. Shanker and M. Aschner, "Identification and characterization of uptake systems for cystine and cysteine in cultured astrocytes and neurons: evidence for methylmercury-targeted disruption of astrocyte transport," Journal of Neuroscience Research, vol. 66, no. 5, pp. 998-1002, 2001.

[18] G. Shanker and M. Aschner, "Methylmercury-induced reactive oxygen species formation in neonatal cerebral astrocytic cultures is attenuated by antioxidants," Molecular Brain Research, vol. 110, no. 1, pp. 85-91, 2003.

[19] Y. Yuan and W. D. Atchison, "Methylmercury-induced increase of intracellular $\mathrm{Ca}^{2+}$ increases spontaneous synaptic current frequency in rat cerebellar slices," Molecular Pharmacology, vol. 71, no. 4, pp. 1109-1121, 2007.

[20] G. Ramanathan and W. D. Atchison, " $\mathrm{Ca}{ }^{2+}$ entry pathways in mouse spinal motor neurons in culture following in vitro exposure to methylmercury," NeuroToxicology, vol. 32, no. 6, pp. 742-750, 2011.

[21] L. H. Tang and E. Aizenman, "The modulation of N-methyl$D$-aspartate receptors by redox and alkylating reagents in rat cortical neurones in vitro," Journal of Physiology, vol. 465, pp. 303-323, 1993.
[22] G. E. N. Kass and S. Orrenius, "Calcium signaling and cytotoxicity," Environmental Health Perspectives, vol. 107, no. 1, pp. 25-35, 1999.

[23] T. L. Limke, S. R. Heidemann, and W. D. Atchison, "Disruption of intraneuronal divalent cation regulation by methylmercury: are specific targets involved in altered neuronal development and cytotoxicity in methylmercury poisoning?" NeuroToxicology, vol. 25, no. 5, pp. 741-760, 2004.

[24] M. R. Bennett, L. Farnell, and W. G. Gibson, "The probability of quantal secretion near a single calcium channel of an active zone," Biophysical Journal, vol. 78, no. 5, pp. 22012221, 2000.

[25] M. Bortolozzi, A. Lelli, and F. Mammano, "Calcium microdomains at presynaptic active zones of vertebrate hair cells unmasked by stochastic deconvolution," Cell Calcium, vol. 44, no. 2, pp. 158-168, 2008.

[26] R. Llinas, M. Sugimori, and R. B. Silver, "Presynaptic calcium concentration microdomains and transmitter release," Journal of Physiology Paris, vol. 86, no. 1-3, pp. 135-138, 1992.

[27] R. Lliná, Msugimori, and R. B. Silver, "The concept of calcium concentration microdomains in synaptic transmission," Neuropharmacology, vol. 34, no. 11, pp. 1443-1451, 1995.

[28] R. Llinas, M. Sugimori, and R. B. Silver, "Time resolved calcium microdomains and synaptic transmission," Journal of Physiology Paris, vol. 89, no. 2, pp. 77-81, 1995.

[29] R. R. Llinás, M. Sugimori, and R. B. Silver, "Localization of calcium concentration microdomains at the active zone in the squid giant synapse," Advances in Second Messenger and Phosphoprotein Research, vol. 29, pp. 133-137, 1994.

[30] H. Kawamata and G. Manfredi, "Mitochondrial dysfunction and intracellular calcium dysregulation in ALS," Mechanisms of Ageing and Development, vol. 131, no. 7-8, pp. 517-526, 2010.

[31] R. Malli and W. F. Graier, "Mitochondrial $\mathrm{Ca}^{2+}$ channels: great unknowns with important functions," FEBS Letters, vol. 584, no. 10, pp. 1942-1947, 2010.

[32] A. Andreyev and G. Fiskum, "Calcium induced release of mitochondrial cytochrome $c$ by different mechanisms selective for brain versus liver," Cell Death and Differentiation, vol. 6, no. 9, pp. 825-832, 1999.

[33] I. Bogeski, R. Kappl, C. Kummerow, R. Gulaboski, M. Hoth, and B. A. Niemeyer, "Redox regulation of calcium ion channels: chemical and physiological aspects," Cell Calcium, vol. 50, no. 5, pp. 407-423, 2011.

[34] M. R. Duchen, "Mitochondria and calcium: from cell signalling to cell death," Journal of Physiology, vol. 529, no. 1, pp. 57-68, 2000.

[35] T. E. Gunter and S. S. Sheu, "Characteristics and possible functions of mitochondrial $\mathrm{Ca}^{2+}$ transport mechanisms," Biochimica et Biophysica Acta, vol. 1787, no. 11, pp. 12911308, 2009.

[36] F. Ichas and J. P. Mazat, "From calcium signaling to cell death: two conformations for the mitochondrial permeability transition pore. Switching from low- to high-conductance state," Biochimica et Biophysica Acta, vol. 1366, no. 1-2, pp. 33-50, 1998.

[37] I. I. Kruman and M. P. Mattson, "Pivotal role of mitochondrial calcium uptake in neural cell apoptosis and necrosis," Journal of Neurochemistry, vol. 72, no. 2, pp. 529-540, 1999.

[38] J. J. Lemasters, A. L. Nieminen, T. Qian et al., "The mitochondrial permeability transition in cell death: a common mechanism in necrosis, apoptosis and autophagy," Biochimica et Biophysica Acta, vol. 1366, no. 1-2, pp. 177-196, 1998. 
[39] M. P. Mattson, "Apoptosis in neurodegenerative disorders," Nature Reviews Molecular Cell Biology, vol. 1, no. 2, pp. 120 129, 2000.

[40] A. P. Somlyo, M. Bond, and A. V. Somlyo, "Calcium content of mitochondria and endoplasmic reticulum in liver frozen rapidly in vivo," Nature, vol. 314, no. 6012, pp. 622-625, 1985.

[41] D. G. Nicholls, "The regulation of extramitochondrial free calcium ion concentration by rat liver mitochondria," Biochemical Journal, vol. 176, no. 2, pp. 463-474, 1978.

[42] D. G. Nicholls and I. D. Scott, "The regulation of brain mitochondrial calcium-ion transport. The role of ATP in the discrimination between kinetic and membrane-potentialdependent calcium-ion efflux mechanisms," Biochemical Journal, vol. 186, no. 3, pp. 833-839, 1980.

[43] S. Von Stockum, E. Basso, V. Petronilli, P. Sabatelli, M. A. Forte, and P. Bernardi, "Properties of $\mathrm{Ca}{ }^{2+}$ transport in mitochondria of Drosophila melanogaster," The Journal of Biological Chemistry, vol. 286, no. 48, pp. 41163-41170, 2011.

[44] M. P. Mattson, F. M. LaFerla, S. L. Chan, M. A. Leissring, P. N. Shepel, and J. D. Geiger, "Calcium signaling in the ER: its role in neuronal plasticity and neurodegenerative disorders," Trends in Neurosciences, vol. 23, no. 5, pp. 222-229, 2000.

[45] S. Pan, S. Y. Ryu, and S. S. Sheu, "Distinctive characteristics and functions of multiple mitochondrial $\mathrm{Ca}^{2+}$ influx mechanisms," Science China Life Sciences, vol. 54, no. 8, pp. 763 769, 2011.

[46] R. Assaly, A. D. De Tassigny, S. Paradis, S. Jacquin, A. Berdeaux, and D. Morin, "Oxidative stress, mitochondrial permeability transition pore opening and cell death during hypoxia-reoxygenation in adult cardiomyocytes," European Journal of Pharmacology, vol. 675, no. 1-3, pp. 6-14, 2012.

[47] A. P. Halestrap and P. Pasdois, "The role of the mitochondrial permeability transition pore in heart disease," Biochimica et Biophysica Acta, vol. 1787, no. 11, pp. 1402-1415, 2009.

[48] R. A. Haworth and D. R. Hunter, "The $\mathrm{Ca}^{2+}$-induced membrane transition in mitochondria. II. Nature of the $\mathrm{Ca}^{2+}$ trigger site," Archives of Biochemistry and Biophysics, vol. 195, no. 2, pp. 460-467, 1979.

[49] D. R. Hunter and R. A. Haworth, "The $\mathrm{Ca}^{2+}$-induced membrane transition in mitochondria. The protective mechanisms," Archives of Biochemistry and Biophysics, vol. 195, no. 2, pp. 453-459, 1979.

[50] D. R. Hunter and R. A. Haworth, "The $\mathrm{Ca}^{2+}$-induced membrane transition in mitochondria. III. Transitional $\mathrm{Ca}^{2+}$ release," Archives of Biochemistry and Biophysics, vol. 195, no. 2, pp. 468-477, 1979.

[51] M. Polunas, A. Halladay, R. B. Tjalkens, M. A. Philbert, H. Lowndes, and K. Reuhl, "Role of oxidative stress and the mitochondrial permeability transition in methylmercury cytotoxicity," NeuroToxicology, vol. 32, no. 5, pp. 526-534, 2011.

[52] L. Ravagnan, T. Roumier, and G. Kroemer, "Mitochondria, the killer organelles and their weapons," Journal of Cellular Physiology, vol. 192, no. 2, pp. 131-137, 2002.

[53] J. Jordán, V. Ceña, and J. H. M. Prehn, "Mitochondrial control of neuron death and its role in neurodegenerative disorders," Journal of Physiology and Biochemistry, vol. 59, no. 2, pp. 129-142, 2003.

[54] J. D. Robertson and S. Orrenius, "Molecular mechanisms of apoptosis induced by cytotoxic chemicals," Critical Reviews in Toxicology, vol. 30, no. 5, pp. 609-627, 2000.

[55] M. W. Ward, D. Kögel, and J. H. M. Prehn, "Neuronal apoptosis: BH3-only proteins the real killers," Journal of Bioenergetics and Biomembranes, vol. 36, no. 4, pp. 295-298, 2004.
[56] M. F. Hare, K. M. McGinnis, and W. D. Atchison, "Methylmercury increases intracellular concentrations of $\mathrm{Ca}++$ and heavy metals in NG108-15 cells," Journal of Pharmacology and Experimental Therapeutics, vol. 266, no. 3, pp. 16261635, 1993.

[57] X. Tan, C. Tang, A. F. Castoldi, L. Manzo, and L. G. Costa, "Effects of inorganic and organic mercury on intracellular calcium levels in rat lymphocytes," Journal of Toxicology and Environmental Health, vol. 38, no. 2, pp. 159-170, 1993.

[58] M. Sue Marty and W. D. Atchison, "Pathways mediating $\mathrm{Ca}^{2+}$ entry in rat cerebellar granule cells following in vitro exposure to methyl mercury," Toxicology and Applied Pharmacology, vol. 147, no. 2, pp. 319-330, 1997.

[59] M. Sue Marty and W. D. Atchison, "Elevations of intracellular $\mathrm{Ca}^{2+}$ as a probable contributor to decreased viability in cerebellar granule cells following acute exposure to methylmercury," Toxicology and Applied Pharmacology, vol. 150, no. 1, pp. 98-105, 1998.

[60] E. Okazaki, Y. Oyama, L. Chikahisa, T. Nagano, N. Katayama, and M. Sakamoto, "Fluorescent estimation on cytotoxicity of methylmercury in dissociated rat cerebellar neurons: its comparison with ionomycin," Environmental Toxicology and Pharmacology, vol. 3, no. 4, pp. 237-244, 1997.

[61] Y. Oyama, F. Tomiyoshi, S. Ueno, K. Furukawa, and L. Chikahisa, "Methylmercury-induced augmentation of oxidative metabolism in cerebellar neurons dissociated from the rats: its dependence on intracellular $\mathrm{Ca}^{2+}$, Brain Research, vol. 660, no. 1, pp. 154-157, 1994.

[62] M. F. Denny and W. D. Atchison, "Mercurial-induced alterations in neuronal divalent cation homeostasis," NeuroToxicology, vol. 17, no. 1, pp. 47-62, 1996.

[63] M. Sakamoto, N. Ikegami, and A. Nakano, "Protective effects of $\mathrm{Ca}^{2+}$ channel blockers against methyl mercury toxicity," Pharmacology and Toxicology, vol. 78, no. 3, pp. 193-199, 1996.

[64] A. F. Castoldi, T. Coccini, S. Ceccatelli, and L. Manzo, "Neurotoxicity and molecular effects of methylmercury," Brain Research Bulletin, vol. 55, no. 2, pp. 197-203, 2001.

[65] S.-Z. Xu, B. Zeng, N. Daskoulidou, G.-L. Chen, S. L. Atkin, and B. Lukhele, "Activation of TRPC cationic channels by mercurial compounds confers the cytotoxicity of mercury exposure," Toxicological Sciences, vol. 125, no. 1, Article ID kfr268, pp. 56-68, 2012.

[66] M. Tepel, S. Löwe, J. R. Nofer, G. Assmann, H. Schlüter, and W. Zidek, "Diadenosine polyphosphates regulate cytosolic calcium in human fibroblast cells by interaction with $\mathrm{P}(2 \mathrm{x})$ purinoceptors coupled to phospholipase C," Biochimica et Biophysica Acta, vol. 1312, no. 2, pp. 145-150, 1996.

[67] N. Macrez-Leprêtre, J. L. Morel, and J. Mironneau, "Effects of phospholipase $\mathrm{C}$ inhibitors on $\mathrm{Ca}^{2+}$ channel stimulation and $\mathrm{Ca}^{2+}$ release from intracellular stores evoked by $\alpha 1 \mathrm{~A}$ - and $\alpha 2 \mathrm{~A}$-adrenoceptors in rat portal vein myocytes," Biochemical and Biophysical Research Communications, vol. 218, no. 1, pp. 30-34, 1996.

[68] J. K. Fahrion, Y. Komuro, Y. Li et al., "Rescue of neuronal migration deficits in a mouse model of fetal Minamata disease by increasing neuronal $\mathrm{Ca}^{2+}$ spike frequency," Proceedings of the National Academy of Sciences of the United States of America, vol. 109, no. 13, pp. 5057-5062, 2012.

[69] F. Mori, K. Tanji, and K. Wakabayashi, "Widespread calcium deposits, as detected using the alizarin red $\mathrm{S}$ technique, in the nervous system of rats treated with dimethyl mercury," Neuropathology, vol. 20, no. 3, pp. 210-215, 2000. 
[70] Y. Yoshino, T. Mozai, and K. Nakao, "Distribution of mercury in the brain and its subcellular units in experimental organic mercury poisoning," Journal of Neurochemistry, vol. 13, pp. 397-406, 1966.

[71] S. C. Bondy and M. McKee, "Disruption of the potential across the synaptosomal plasma membrane and mitochondria by neurotoxic agents," Toxicology Letters, vol. 58, no. 1, pp. 13-21, 1991.

[72] M. F. Hare and W. D. Atchison, "Comparative action of methylmercury and divalent inorganic mercury on nerve terminal and intraterminal mitochondrial membrane potentials," Journal of Pharmacology and Experimental Therapeutics, vol. 261, no. 1, pp. 166-172, 1992.

[73] T. L. Limke and W. D. Atchison, "Acute exposure to methylmercury opens the mitochondrial permeability transition pore in rat cerebellar granule cells," Toxicology and Applied Pharmacology, vol. 178, no. 1, pp. 52-61, 2002.

[74] C. Wagner, A. P. Vargas, D. H. Roos et al., "Comparative study of quercetin and its two glycoside derivatives quercitrin and rutin against methylmercury ( $\mathrm{MeHg}$ )-induced ROS production in rat brain slices," Archives of Toxicology, vol. 84, no. 2, pp. 89-97, 2010.

[75] S. Yee and B. H. Choi, "Oxidative stress in neurotoxic effects of methylmercury poisoning," NeuroToxicology, vol. 17, no. 1, pp. 17-26, 1996.

[76] B. J. Shenker, T. L. Guo, O. Insug, and I. M. Shapiro, "Induction of apoptosis in human T-cells by methyl mercury: temporal relationship between mitochondrial dysfunction and loss of reductive reserve," Toxicology and Applied Pharmacology, vol. 157, no. 1, pp. 23-35, 1999.

[77] B. J. Shenker, L. Pankoski, A. Zekavat, and I. M. Shapiro, "Mercury-induced apoptosis in human lymphocytes: caspase activation is linked to redox status," Antioxidants and Redox Signaling, vol. 4, no. 3, pp. 379-389, 2002.

[78] N. Sone, M. K. Larsstuvold, and Y. Kagawa, "Effect of methyl mercury on phosphorylation, transport, and oxidation in mammalian mitochondria," Journal of Biochemistry, vol. 82, no. 3, pp. 859-868, 1977.

[79] M. A. Verity, W. J. Brown, and M. Cheung, "Organic mercurial encephalopathy: in vivo and in vitro effects of methyl mercury on synaptosomal respiration," Journal of Neurochemistry, vol. 25, no. 6, pp. 759-766, 1975.

[80] B. A. Fowler and J. S. Woods, "Ultrastructural and biochemical changes in renal mitochondria during chronic oral methyl mercury exposure. The relationship to renal function," Experimental and Molecular Pathology, vol. 27, no. 3, pp. 403-412, 1977.

[81] P. Bernardi, K. M. Broekemeier, and D. R. Pfeiffer, "Recent progress on regulation of the mitochondrial permeability transition pore; A cyclosporin-sensitive pore in the inner mitochondrial membrane," Journal of Bioenergetics and Biomembranes, vol. 26, no. 5, pp. 509-517, 1994.

[82] A. P. Halestrap, "What is the mitochondrial permeability transition pore?" Journal of Molecular and Cellular Cardiology, vol. 46, no. 6, pp. 821-831, 2009.

[83] J. J. Lemasters, T. P. Theruvath, Z. Zhong, and A. L. Nieminen, "Mitochondrial calcium and the permeability transition in cell death," Biochimica et Biophysica Acta, vol. 1787, no. 11, pp. 1395-1401, 2009.

[84] A. L. Nieminen, T. G. Petrie, J. J. Lemasters, and W. R. Selman, "Cyclosporin A delays mitochondrial depolarization induced by N-methyl-D-aspartate in cortical neurons: evidence of the mitochondrial permeability transition," Neuroscience, vol. 75, no. 4, pp. 993-997, 1996.
[85] T. L. Limke, J. K. L. Otero-Montañez, and W. D. Atchison, "Evidence for interactions between intracellular calcium stores during methylmercury-induced intracellular calcium dysregulation in rat cerebellar granule neurons," Journal of Pharmacology and Experimental Therapeutics, vol. 304, no. 3, pp. 949-958, 2003.

[86] P. G. Sullivan, A. G. Rabchevsky, P. C. Waldmeier, and J. E. Springer, "Mitochondrial permeability transition in CNS trauma: cause or effect of neuronal cell death?" Journal of Neuroscience Research, vol. 79, no. 1-2, pp. 231-239, 2005.

[87] H. Friberg, M. Ferrand-Drake, F. Bengtsson, A. P. Halestrap, and T. Wieloch, "Cyclosporin A, but not FK 506, protects mitochondria and neurons against hypoglycemic damage and implicates the mitochondrial permeability transition in cell death," Journal of Neuroscience, vol. 18, no. 14, pp. 51515159, 1998.

[88] L. M. Loew, W. Carrington, R. A. Tuft, and F. S. Fay, "Physiological cytosolic $\mathrm{Ca}^{2+}$ transients evoke concurrent mitochondrial depolarizations," Proceedings of the National Academy of Sciences of the United States of America, vol. 91, no. 26, pp. 12579-12583, 1994.

[89] O. Insug, S. Datar, C. J. Koch, I. M. Shapiro, and B. J. Shenker, "Mercuric compounds inhibit human monocyte function by inducing apoptosis: evidence for formation of reactive oxygen species, development of mitochondrial membrane permeability transition and loss of reductive reserve," Toxicology, vol. 124, no. 3, pp. 211-224, 1997.

[90] P. Bernardi, P. Veronese, and V. Petronilli, "Modulation of the mitochondrial cyclosporin A-sensitive permeability transition pore. I. Evidence for two separate $\mathrm{Me}^{2+}$ binding sites with opposing effects on the pore open probability," The Journal of Biological Chemistry, vol. 268, no. 2, pp. 10051010, 1993.

[91] V. Petronilli, C. Cola, and P. Bernardi, "Modulation of the mitochondrial cyclosporin A-sensitive permeability transition pore. II. The minimal requirements for pore induction underscore a key role for transmembrane electrical potential, matrix $\mathrm{pH}$, and matrix $\mathrm{Ca}^{2+}, "$ The Journal of Biological Chemistry, vol. 268, no. 2, pp. 1011-1016, 1993.

[92] P. B. Simpson and J. T. Russell, "Mitochondrial $\mathrm{Ca}^{2+}$ uptake and release influence metabotropic and ionotropic cytosolic $\mathrm{Ca}^{2+}$ responses in rat oligodendrocyte progenitors," Journal of Physiology, vol. 508, no. 2, pp. 413-426, 1998.

[93] K. K. Gunter and T. E. Gunter, "Transport of calcium by mitochondria," Journal of Bioenergetics and Biomembranes, vol. 26, no. 5, pp. 471-485, 1994.

[94] A. M. Byrne, "Contribution of increased mitochondrial free $\mathrm{Ca}^{2+}$ to the mitochondrial permeability transition induced by tert-butylhydroperoxide in rat hepatocytes," Hepatology, vol. 29, no. 5, pp. 1523-1531, 1999.

[95] T. L. Limke, J. J. Bearss, and W. D. Atchison, "Acute exposure to methylmercury causes $\mathrm{Ca}^{2+}$ dysregulation and neuronal death in rat cerebellar granule cells through an M3 muscarinic receptor-linked pathway," Toxicological Sciences, vol. 80, no. 1, pp. 60-68, 2004.

[96] M. F. Hare and W. D. Atchison, "Methylmercury mobilizes $\mathrm{Ca}++$ from intracellular stores sensitive to inositol 1,4,5trisphosphate in NG108-15 cells," Journal of Pharmacology and Experimental Therapeutics, vol. 272, no. 3, pp. 10161023, 1995.

[97] S. L. Budd and D. G. Nicholls, "A reevaluation of the role of mitochondria in neuronal $\mathrm{Ca}^{2+}$ homeostasis," Journal of Neurochemistry, vol. 66, no. 1, pp. 403-411, 1996. 
[98] M. R. Duchen, "Mitochondria and $\mathrm{Ca}^{2+}$ in cell physiology and pathophysiology," Cell Calcium, vol. 28, no. 5-6, pp. 339$348,2000$.

[99] S. Ceccatelli, E. Daré, and M. Moors, "Methylmercuryinduced neurotoxicity and apoptosis," Chemico-Biological Interactions, vol. 188, no. 2, pp. 301-308, 2010.

[100] P. Pietta, P. Simonetti, C. Gardana, and P. Mauri, “Trolox equivalent antioxidant capacity (TEAC) of Ginkgo biloba flavonol and Camellia sinensis catechin metabolites," Journal of Pharmaceutical and Biomedical Analysis, vol. 23, no. 1, pp. 223-226, 2000.

[101] R. d. P. Martins, H. d. C. Braga, A. P. da Silva et al., "Synergistic neurotoxicity induced by methylmercury and quercetin in mice," Food and Chemical Toxicology, vol. 47, no. 3, pp. 645-649, 2009.

[102] A. Dreiem and R. F. Seegal, "Methylmercury-induced changes in mitochondrial function in striatal synaptosomes are calcium-dependent and ROS-independent," NeuroToxicology, vol. 28, no. 4, pp. 720-726, 2007.

[103] M. Valko, H. Morris, and M. T. D. Cronin, "Metals, toxicity and oxidative stress," Current Medicinal Chemistry, vol. 12, no. 10, pp. 1161-1208, 2005.

[104] Q. Cai, R. O. Rahn, and R. Zhang, "Dietary flavonoids, quercetin, luteolin and genistein, reduce oxidative DNA damage and lipid peroxidation and quench free radicals," Cancer Letters, vol. 119, no. 1, pp. 99-107, 1997.

[105] J. L. Franco, H. C. Braga, J. Stringari et al., "Mercurialinduced hydrogen peroxide generation in mouse brain mitochondria: protective effects of quercetin," Chemical Research in Toxicology, vol. 20, no. 12, pp. 1919-1926, 2007.

[106] G. M. R. D. S. Lucena, J. L. Franco, C. M. Ribas et al., "Cipura paludosa extract prevents methyl mercury-induced neurotoxicity in mice," Basic and Clinical Pharmacology and Toxicology, vol. 101, no. 2, pp. 127-131, 2007.

[107] M. Farina, F. Campos, I. Vendrell et al., "Probucol increases glutathione peroxidase-1 activity and displays long-lasting protection against methylmercury toxicity in cerebellar granule cells," Toxicological Sciences, vol. 112, no. 2, pp. 416-426, 2009.

[108] M. Farina, F. A. A. Soares, G. Zeni, D. O. Souza, and J. B. T. Rocha, "Additive pro-oxidative effects of methylmercury and ebselen in liver from suckling rat pups," Toxicology Letters, vol. 146, no. 3, pp. 227-235, 2004.

[109] J. Y. Chang and P. F. Tsai, "Prevention of methylmercuryinduced mitochondrial depolarization, glutathione depletion and cell death by 15-deoxy-delta-12,14-prostaglandin J2," NeuroToxicology, vol. 29, no. 6, pp. 1054-1061, 2008.

[110] D. H. Roos, R. L. Puntel, M. M. Santos et al., "Guanosine and synthetic organoselenium compounds modulate methylmercury-induced oxidative stress in rat brain cortical slices: involvement of oxidative stress and glutamatergic system," Toxicology in Vitro, vol. 23, no. 2, pp. 302-307, 2009.

[111] P. B. Tchounwou, W. K. Ayensu, N. Ninashvili, and D. Sutton, "Environmental exposure to mercury and its toxicopathologic implications for public health," Environmental Toxicology, vol. 18, no. 3, pp. 149-175, 2003.

[112] T. W. Clarkson, L. Magos, and G. J. Myers, "The toxicology of mercury-current exposures and clinical manifestations," The New England Journal of Medicine, vol. 349, no. 18, pp. 17311737, 2003.

[113] M. C. Carvalho, J. L. Franco, H. Ghizoni et al., "Effects of 2,3-dimercapto-1-propanesulfonic acid (DMPS) on methylmercury-induced locomotor deficits and cerebellar toxicity in mice," Toxicology, vol. 239, no. 3, pp. 195-203, 2007.
[114] S. D. Pingree, P. L. Simmonds, and J. S. Woods, "Effects of 2,3-dimercapto-1-propanesulfonic acid (DMPS) on tissue and urine mercury levels following prolonged methylmercury exposure in rats," Toxicological Sciences, vol. 61, no. 2, pp. 224-233, 2001.

[115] M. Farina, J. L. Franco, C. M. Ribas et al., "Protective effects of Polygala paniculata extract against methylmercury-induced neurotoxicity in mice," Journal of Pharmacy and Pharmacology, vol. 57, no. 11, pp. 1503-1508, 2005.

[116] M. R. Campos-Esparza, M. V. Sánchez-Gómez, and C. Matute, "Molecular mechanisms of neuroprotection by two natural antioxidant polyphenols," Cell Calcium, vol. 45, no. 4, pp. 358-368, 2009.

[117] C. J. S. Passos, D. Mergler, M. Fillion et al., "Epidemiologic confirmation that fruit consumption influences mercury exposure in riparian communities in the Brazilian Amazon," Environmental Research, vol. 105, no. 2, pp. 183-193, 2007.

[118] B. D. Laird, C. Shade, N. Gantner, H. M. Chan, and S. D. Siciliano, "Bioaccessibility of mercury from traditional northern country foods measured using an in vitro gastrointestinal model is independent of mercury concentration," Science of the Total Environment, vol. 407, no. 23, pp. 6003-6008, 2009.

[119] C. A. Rice-Evans, N. J. Miller, and G. Paganga, "Structureantioxidant activity relationships of flavonoids and phenolic acids," Free Radical Biology and Medicine, vol. 20, no. 7, pp. 933-956, 1996.

[120] C. Rice-Evans, "Flavonoid antioxidants," Current Medicinal Chemistry, vol. 8, no. 7, pp. 797-807, 2001.

[121] P. G. Pietta, "Flavonoids as antioxidants," Journal of Natural Products, vol. 63, no. 7, pp. 1035-1042, 2000.

[122] F. C. Meotti, R. Fachinetto, L. C. Maffi et al., "Antinociceptive action of myricitrin: involvement of the $\mathrm{K}+$ and $\mathrm{Ca}^{2+}$ channels," European Journal of Pharmacology, vol. 567, no. 3, pp. 198-205, 2007.

[123] N. A. Kelsey, H. M. Wilkins, and D. A. Linseman, "Nutraceutical antioxidants as novel neuroprotective agents," Molecules, vol. 15, no. 11, pp. 7792-7814, 2010.

[124] J. Dai and R. J. Mumper, "Plant phenolics: extraction, analysis and their antioxidant and anticancer properties," Molecules, vol. 15, no. 10, pp. 7313-7352, 2010.

[125] K. H. Lee and E. M. Choi, "Myricetin, a naturally occurring flavonoid, prevents 2-deoxy-d-ribose induced dysfunction and oxidative damage in osteoblastic MC3T3-E1 cells," European Journal of Pharmacology, vol. 591, no. 1-3, pp. 1-6, 2008.

[126] R. J. Williams, J. P. E. Spencer, and C. Rice-Evans, "Flavonoids: antioxidants or signalling molecules?" Free Radical Biology and Medicine, vol. 36, no. 7, pp. 838-849, 2004.

[127] Y. Shimmyo, T. Kihara, A. Akaike, T. Niidome, and H. Sugimoto, "Multifunction of myricetin on $A \beta$ : neuroprotection via a conformational change of $\mathrm{A} \beta$ and reduction of $\mathrm{A} \beta$ via the interference of secretases," Journal of Neuroscience Research, vol. 86, no. 2, pp. 368-377, 2008.

[128] S. Das, B. Nageshwar Rao, and B. S. Satish Rao, "Mangiferin attenuates methylmercury induced cytotoxicity against IMR32, human neuroblastoma cells by the inhibition of oxidative stress and free radical scavenging potential," ChemicoBiological Interactions, vol. 193, no. 2, pp. 129-140, 2011.

[129] J. L. Franco, T. Posser, F. Missau et al., "Structure-activity relationship of flavonoids derived from medicinal plants in preventing methylmercury-induced mitochondrial dysfunction," Environmental Toxicology and Pharmacology, vol. 30, no. 3, pp. 272-278, 2010. 
[130] C. A. Rice-Evans and N. J. Miller, "Antioxidant activities of flavonoids as bioactive components of food," Biochemical Society Transactions, vol. 24, no. 3, pp. 790-795, 1996.

[131] J. B. Harborne, "Nature, distribution and function of plant flavonoids," Progress in Clinical and Biological Research, vol. 213, pp. 15-24, 1986.

[132] F. Shahidi and P. K. Wanasundara, "Phenolic antioxidants," Critical Reviews in Food Science and Nutrition, vol. 32, no. 1, pp. 67-103, 1992.

[133] A. Saija, M. Scalese, M. Lanza, D. Marzullo, F. Bonina, and F. Castelli, "Flavonoids as antioxidant agents: importance of their interaction with biomembranes," Free Radical Biology and Medicine, vol. 19, no. 4, pp. 481-486, 1995.

[134] H. E. Ganther, C. Goudie, M. L. Sunde et al., "Selenium: relation to decreased toxicity of methylmercury added to diets containing tuna," Science, vol. 175, no. 4026, pp. 11221124, 1972.

[135] N. V. C. Ralston and L. J. Raymond, “Dietary selenium's protective effects against methylmercury toxicity," Toxicology, vol. 278, no. 1, pp. 112-123, 2010.

[136] C. W. Nogueira and J. B. T. Rocha, "Toxicology and pharmacology of selenium: emphasis on synthetic organoselenium compounds," Archives of Toxicology, vol. 85, no. 11, pp. 13131359, 2011.

[137] D. F. Meinerz, M. D. Paula, B. Comparsi et al., "Protective effects of organoselenium compounds against methylmercury-induced oxidative stress in mouse brain mitochondrialenriched fractions," Brazilian Journal of Medical and Biological Research, vol. 44, no. 11, pp. 1156-1163, 2011.

[138] A. S. De Freitas and J. B. T. Rocha, "Diphenyl diselenide and analogs are substrates of cerebral rat thioredoxin reductase: a pathway for their neuroprotective effects," Neuroscience Letters, vol. 503, no. 1, pp. 1-5, 2011.

[139] M. B. Moretto, C. Funchal, A. Q. Santos et al., "Ebselen protects glutamate uptake inhibition caused by methyl mercury but does not by Hg2+," Toxicology, vol. 214, no. 1-2, pp. 5766, 2005.

[140] M. Farina, K. C. S. Dahm, F. D. Schwalm et al., "Methylmercury increases glutamate release from brain synaptosomes and glutamate uptake by cortical slices from suckling rat pups: modulatory effect of ebselen," Toxicological Sciences, vol. 73, no. 1, pp. 135-140, 2003.

[141] C. Funchal, M. B. Moretto, L. Vivian, G. Zeni, J. B. T. Rocha, and R. Pessoa-Pureur, "Diphenyl ditelluride- and methylmercury-induced hyperphosphorilation of the high molecular weight neurofilament subunit is prevented by organoselenium compounds in cerebral cortex of young rats," Toxicology, vol. 222, no. 1-2, pp. 143-153, 2006.

[142] A. Dreiem, C. C. Gertz, and R. F. Seegal, "The effects of methylmercury on mitochondrial function and reactive oxygen species formation in rat striatal synaptosomes are agedependent," Toxicological Sciences, vol. 87, no. 1, pp. 156-162, 2005. 

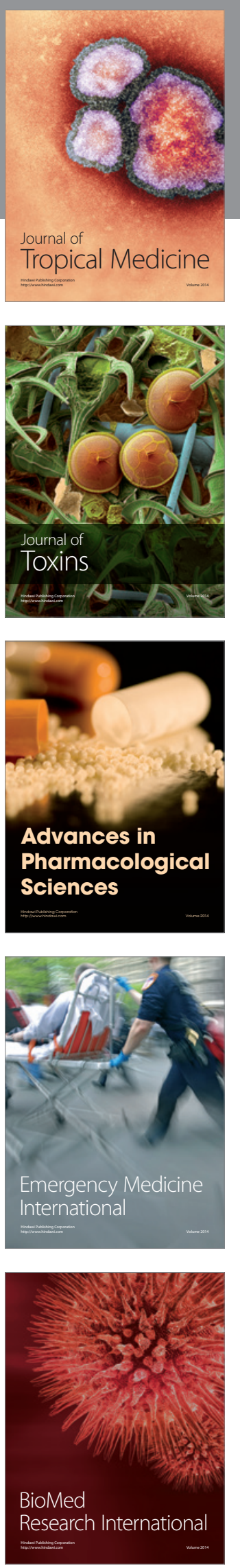
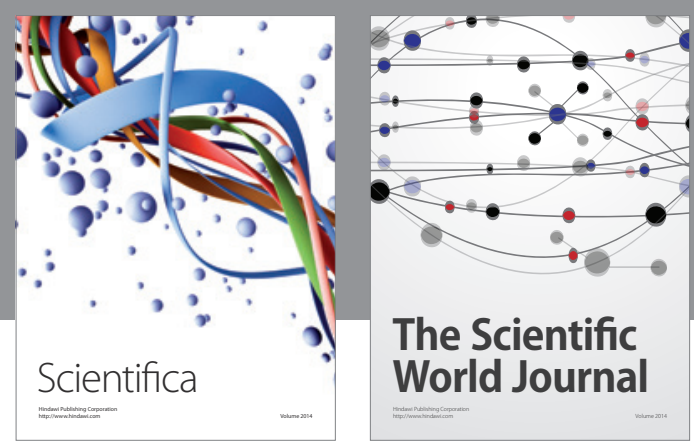

The Scientific World Journal
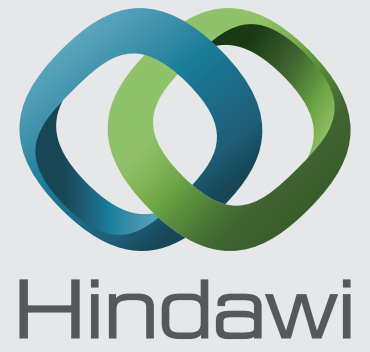

Submit your manuscripts at

http://www.hindawi.com
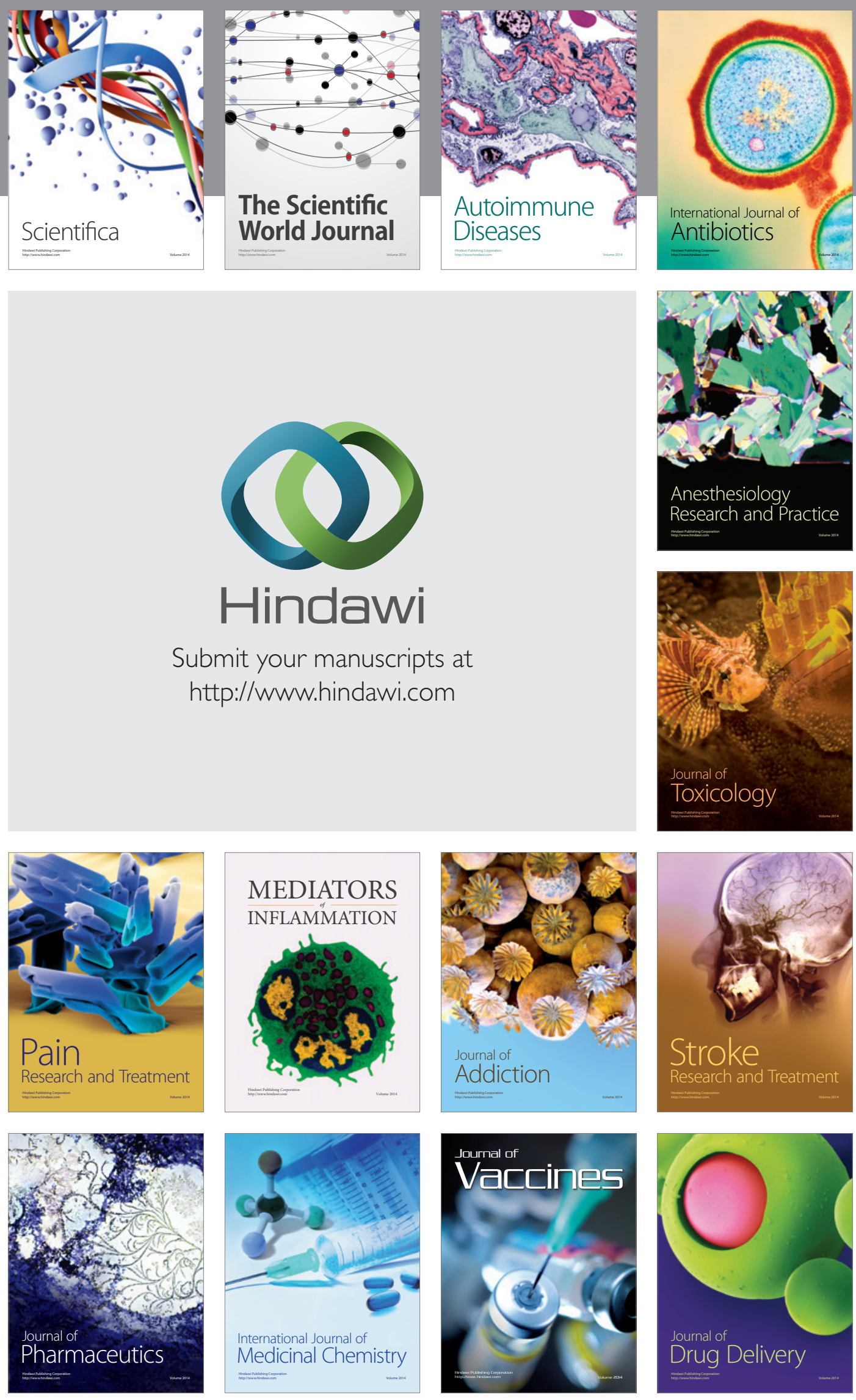